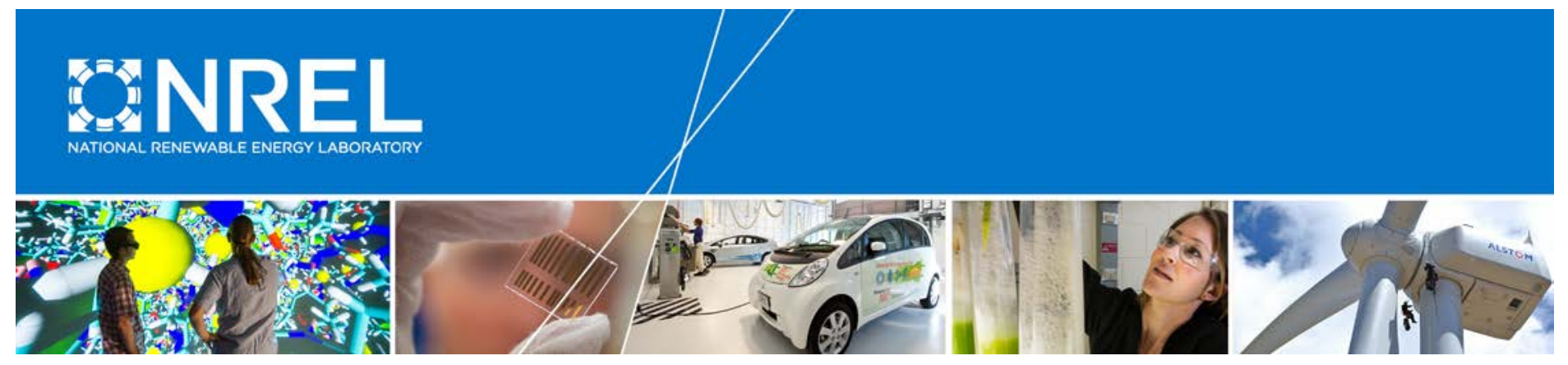

\title{
Structural Testing of the Blade Reliability Collaborative Effect of Defect Wind Turbine Blades
}

\author{
M. Desmond and S. Hughes \\ National Renewable Energy Laboratory \\ J. Paquette \\ Sandia National Laboratories
}

NREL is a national laboratory of the U.S. Department of Energy Office of Energy Efficiency \& Renewable Energy Operated by the Alliance for Sustainable Energy, LLC

This report is available at no cost from the National Renewable Energy Laboratory (NREL) at www.nrel.gov/publications.

Technical Report

NREL/TP-5000-63512

June 2015

Contract No. DE-AC36-08GO28308 


\title{
Structural Testing of the Blade Reliability Collaborative Effect of Defect Wind Turbine Blades
}

\author{
M. Desmond and S. Hughes \\ National Renewable Energy Laboratory \\ J. Paquette \\ Sandia National Laboratories
}

Prepared under Task No. WE14.3A04

NREL is a national laboratory of the U.S. Department of Energy Office of Energy Efficiency \& Renewable Energy Operated by the Alliance for Sustainable Energy, LLC

This report is available at no cost from the National Renewable Energy Laboratory (NREL) at www.nrel.gov/publications.

National Renewable Energy Laboratory 15013 Denver West Parkway Golden, CO 80401

303-275-3000 • www.nrel.gov

\section{Technical Report}

NREL/TP-5000-63512

June 2015

Contract No. DE-AC36-08G028308 


\title{
NOTICE
}

This report was prepared as an account of work sponsored by an agency of the United States government. Neither the United States government nor any agency thereof, nor any of their employees, makes any warranty, express or implied, or assumes any legal liability or responsibility for the accuracy, completeness, or usefulness of any information, apparatus, product, or process disclosed, or represents that its use would not infringe privately owned rights. Reference herein to any specific commercial product, process, or service by trade name, trademark, manufacturer, or otherwise does not necessarily constitute or imply its endorsement, recommendation, or favoring by the United States government or any agency thereof. The views and opinions of authors expressed herein do not necessarily state or reflect those of the United States government or any agency thereof.

This report is available at no cost from the National Renewable Energy Laboratory (NREL) at www.nrel.gov/publications.

Available electronically at SciTech Connect http:/www.osti.gov/scitech

Available for a processing fee to U.S. Department of Energy and its contractors, in paper, from:

\author{
U.S. Department of Energy \\ Office of Scientific and Technical Information \\ P.O. Box 62 \\ Oak Ridge, TN 37831-0062 \\ OSTI http://www.osti.gov \\ Phone: 865.576.8401 \\ Fax: 865.576.5728 \\ Email: reports@osti.gov
}

Available for sale to the public, in paper, from:

\author{
U.S. Department of Commerce \\ National Technical Information Service \\ 5301 Shawnee Road \\ Alexandra, VA 22312 \\ NTIS http://www.ntis.gov \\ Phone: 800.553 .6847 or 703.605 .6000 \\ Fax: 703.605.6900 \\ Email: orders@ntis.gov
}




\section{Acknowledgments}

This work was supported by the U.S. Department of Energy under Contract No. DE-AC36-08GO28308 with the National Renewable Energy Laboratory. Funding for the work was provided by the DOE Office of Energy Efficiency and Renewable Energy, Wind and Water Power Technologies Office.

The authors would like to thank Mike Jenks, Bill Gage, Ryan Beach, Dave Snowberg, and Sheri Anstedt of the National Renewable Energy Laboratory in the preparation, performance, reporting, and publishing of the tests. The authors would also like to thank Al Beattie of Sandia National Laboratories, and Trey Riddle and Jared Nelson of Montana State University for support and collaboration during testing. 


\section{Nomenclature}

$\begin{array}{ll}\text { AE } & \text { acoustic emission } \\ \text { BRC } & \text { Blade Reliability Collaborative } \\ \text { BSDS } & \text { Blade Systems Design Study } \\ \text { CG } & \text { center of gravity } \\ \text { DEL } & \text { damage equivalent load } \\ \text { DIC } & \text { digital image correlation } \\ \text { DOE } & \text { U.S. Department of Energy } \\ \text { EDAS } & \text { Ethercat Data Acquisition System } \\ \text { HP } & \text { high pressure } \\ \text { Hz } & \text { hertz } \\ \text { kN } & \text { kilonewton } \\ \text { LP } & \text { low pressure } \\ \text { LVDT } & \text { linear variable differential transformer } \\ \text { m } & \text { meter } \\ \text { mm } & \text { millimeter } \\ \text { MN } & \text { meganewton } \\ \text { MPa } & \text { megapascal } \\ \text { MSU } & \text { Montana State University } \\ \text { NI } & \text { National Instruments } \\ \text { NREL } & \text { National Renewable Energy Laboratory } \\ \text { NWTC } & \text { National Wind Technology Center } \\ \text { R } & \text { r-ratio } \\ \text { S-N slope } & \text { Slope of a constant amplitude log-log stress versus cycle count curve } \\ \text { SNL } & \text { Sandia National Laboratories } \\ & \end{array}$




\section{Table of Contents}

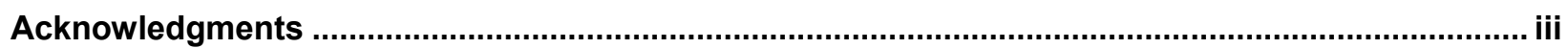

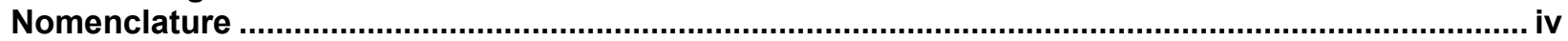

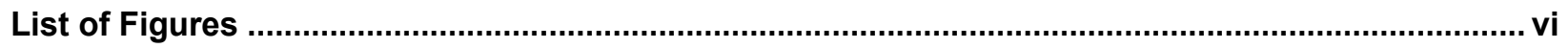

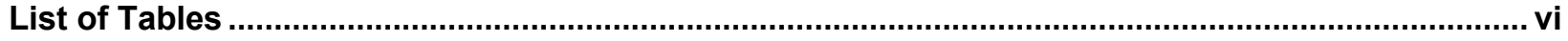

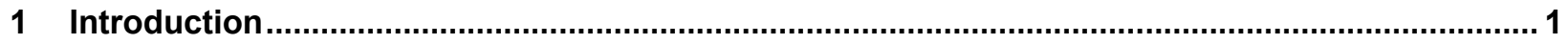

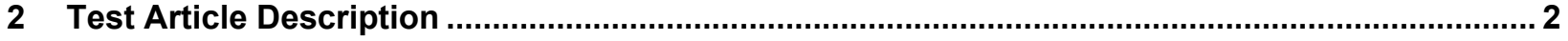

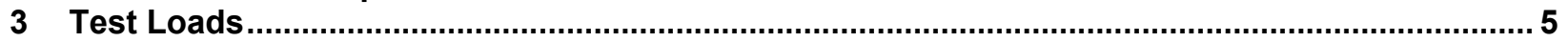

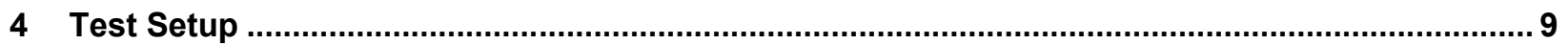

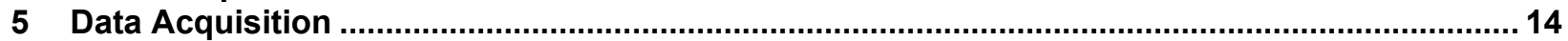

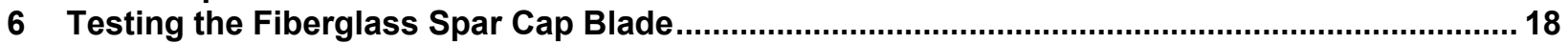

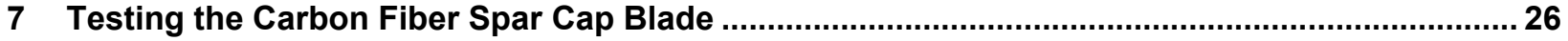

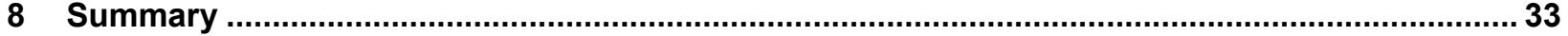

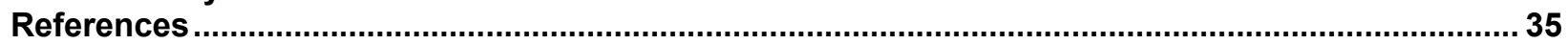




\section{List of Figures}

Figure 1. Fiberglass (top) and carbon (bottom) spar cap test articles prior to testing. ...................... 3

Figure 2. Characteristic test flapwise bending moments for fiberglass and carbon fiber spar cap blades

Figure 3. Blade cross section showing blade components and the test coordinate system............ 6

Figure 4. Mechanical setup and resulting test bending moments for outboard (top), midspan (middle), and inboard (bottom) load cases .................................................................................. 7

Figure 5. Setup and applied moment for load cases applied with strut at the 6 -m station.................. 8

Figure 6. Fatigue load case generalization, depicting individual load blocks..................................... 8

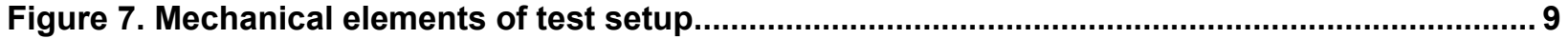

Figure 8. Photograph of the blade root to test stand fixture.......................................................... 10

Figure 9. Test setup for loading the carbon spar cap blade at the $7-\mathrm{m}$ station............................... 11

Figure 10. Actuator to blade attachment methods - direct attachment (left), load saddle (right)

Figure 11. Test setup for actuator at the 7-m station and restraint strut at the $6-\mathrm{m}$ station............. 13

Figure 12. Digital image correlation imaging pattern painted on blade surface over areas containing flaws.

Figure 13. Acoustic emission sensors mounted to the low-pressure surface of the blade. ............ 16

Figure 14. Moment range versus cycle applied to the $6.2-\mathrm{m}$ station, fiberglass spar cap blade ..... 18

Figure 15. Fiberglass spar cap blade failure area at the 6.2-m station, low-pressure surface......... 20

Figure 16. Moment range versus cycle at the $3.75-\mathrm{m}$ station, fiberglass spar cap blade ................. 21

Figure 17. Fiberglass spar cap blade, high-pressure side damage area at the $3.75-\mathrm{m}$ station prior to catastrophic failure.

Figure 18. Fiberglass spar cap blade, high-pressure side catastrophic failure at the 3.75-m station

Figure 19. Fiberglass spar cap blade, damage area at the 1.2-m station on the high-pressure

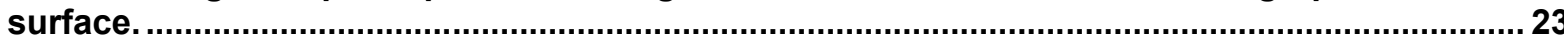

Figure 20. Fiberglass spar cap blade, damage equivalent load curves for each failure station ...... 24

Figure 21. Moment range versus cycle number at the 6.2-m station, carbon fiber spar cap blade

Figure 22. Carbon fiber spar cap blade, low-pressure side failure area at the 6.2-m station. .......... 27

Figure 23. Moment range versus cycle number at the 5-m station, carbon fiber spar cap blade

Figure 24. Carbon fiber spar cap blade, failure region on low-pressure surface at the 5-m station.

Figure 25. Carbon fiber spar cap blade, DEL curves at failure stations of $5 \mathrm{~m}$ and $6.2 \mathrm{~m} \ldots \ldots \ldots \ldots . . . . .30$

Figure 26. Static load steps applied at the $4.37-\mathrm{m}$ station, carbon spar cap blade .......................... 31

Figure 27. Failure area on the low-pressure side at the 2.25-m station, carbon fiber spar cap blade.

Figure 28. Comparison of target bending moment distribution and applied DEL at failure locations.

\section{List of Tables}

Table 1. Flaws of Interest Monitored During Full-Scale Laboratory Testing 4

Table 2. Nominal Resistance-Type Strains and Blade Displacements at the Load Application Station for the Fiberglass Spar Cap Blade

Table 3. Nominal Resistance-Type Strains and Blade Displacements at the Load Application Station for the Carbon Fiber Spar Cap Blade

Table 4. Summary of failures observed During Full-Scale Structural Testing of the BRC Blades 


\section{Introduction}

Two 8.3-meter $(\mathrm{m})$ wind turbine blades intentionally constructed with manufacturing flaws were tested to failure at the National Wind Technology Center (NWTC) at the National Renewable Energy Laboratory (NREL) south of Boulder, Colorado. Two blades were tested; one blade was manufactured with a fiberglass spar cap and the second blade was manufactured with a carbon fiber spar cap. Test loading primarily consisted of flap fatigue loading of the blades, with one quasi-static ultimate load case applied to the carbon fiber spar cap blade. Results of the test program were intended to provide the full-scale test data needed for validation of model and coupon test results of the effect of defects in wind turbine blade composite materials. Testing was part of the Blade Reliability Collaborative (BRC) led by Sandia National Laboratories (SNL). The BRC seeks to develop a deeper understanding of the causes of unexpected blade failures (Paquette 2012), and to develop methods to enable blades to survive to their expected operational lifetime. Recent work in the BRC includes examining and characterizing flaws and defects known to exist in wind turbine blades from manufacturing processes (Riddle et al. 2011). Recent results from reliability databases show that wind turbine rotor blades continue to be a leading contributor to turbine downtime (Paquette 2012).

Prior studies and coupon-level testing were carried out to characterize common types of flaws and defects observed in wind turbine blades (Riddle 2011). These studies and testing were used to inform the development of full-scale wind turbine blades that could be used to test the effect of defects in full-scale blades. Manufacturing and testing of 8.3-m test blades (compared to 50-m and larger utility-scale turbine blades used today) kept program costs within reason while still allowing characterization of the flaws in a complete blade. Because both fiberglass and carbon fiber are used in the spar caps of modern turbine blades, two different blade test articles with intentional defects were manufactured. Instrumentation and sensing techniques used during testing included point and full-field strain measurements, acoustic emission, and thermography. This report describes the full-scale structural testing performed between March and September of 2013 of BRC 8.3-m wind turbine blades with purpose-built flaws. 


\section{Test Article Description}

The molds and nominal laminate schedule of the SNL 8.3-m Blade Systems Design Study (BSDS) blade were used for manufacturing the BRC blades. The BSDS blade platform was chosen because of the availability of previous test data, proportional geometric similarity to modern blade designs, and efficient structural design. The BSDS blade was designed for research demonstration purposes, both for structural studies of material and manufacturing needs, and field performance validation testing on a 100-kilowatt $(\mathrm{kW})$ stall-regulated turbine. Novel aspects of the BSDS design included constant-width carbon fiber spar caps and flatback airfoils on the inner spans of the blade. Static strength and fatigue testing of the BSDS blades was performed at NREL in 2006 (Paquette 2007).

Two different blades were tested; one blade was manufactured with a fiberglass spar cap, and the second blade was manufactured with a carbon fiber spar cap. The fiberglass spar cap was the same thickness as the carbon fiber spar cap, but was made wider to achieve approximately the same flap bending stiffness for both blades. An epoxy resin infusion process was used to fabricate the high-pressure and low-pressure blade skins and single shear web. The skins and shear web were then bonded together. The balance of materials for both blades included fiberglass reinforcement at the leading and trailing edges, fiberglass double-bias fabric in the skin of the blade, balsa wood core material in the leading and trailing-edge panels of the skins, and a fiberglass root build-up. The blade root attachment design uses twenty-four 5/8-inchthreaded studs. The threaded studs are directly laminated into the blade root build-up during skin infusion. Figure 1 shows photos of the blades as delivered to the NWTC, the fiberglass (green) and carbon fiber (black) spar caps are visible because the blades were fabricated with a clear gel coat. 


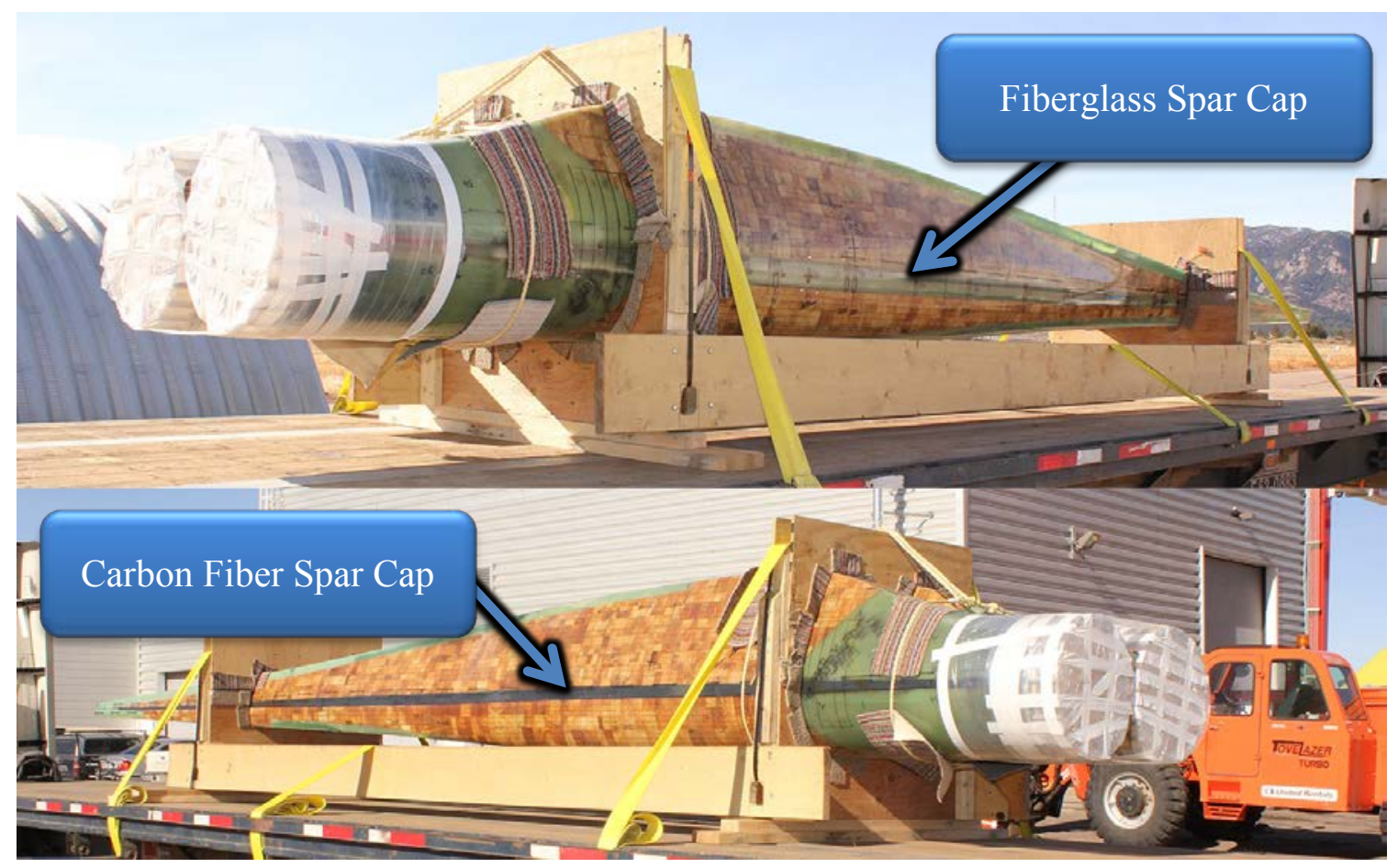

Figure 1. Fiberglass (top) and carbon (bottom) spar cap test articles prior to testing. Photo by Michael Desmond, NREL 32516

The weight of the fiberglass spar cap blade was measured to be 1.48 kilonewtons $(\mathrm{kN})$, with a center of gravity (CG) $2.22 \mathrm{~m}$ from the root of the blade. The weight of the carbon spar cap blade was measured to be $1.38 \mathrm{kN}$, with a CG $2.12 \mathrm{~m}$ from the root of the blade.

The test articles were manufactured by TPI Composites in Warren, Rhode Island. Staff from SNL and Montana State University (MSU) participated in the manufacturing of the blades, assisting with the design and implementation of the flaws into the full blade structure. Flaws that were intentionally built into the blade include:

- Out-of-plane waves - waves introduced in the spar cap laminate with the peaks and troughs of the wave in the direction of the thickness of the blade

- In-plane waves - waves in the spar cap laminate with the peaks and troughs of the wave towards the leading and trailing edge of the blade

- Porosity/voids - air pockets and bubbles introduced in the matrix material of the laminate and bondlines

- Delaminations and dry-spots - Teflon strips placed to simulate interlaminar and bondline gaps.

Flaws were assigned by MSU to have different magnitudes of severity based on prior testing and analysis. A large magnitude severity would imply the greatest potential to reduce the structural performance of the blade. The flaws identified by MSU to have the greatest impact on the performance of the blade are listed in Table 1. These flaws and the areas surrounding the flaws 
were the primary areas of interest during structural testing. Load cases used during testing were designed to apply characteristic flapwise moments at the blade spans where large magnitude severity (referred to as 'critical') flaws were located. Instrumentation and sensing systems were also configured to focus on areas around these flaws.

Table 1. Flaws of Interest Monitored During Full-Scale Laboratory Testing

\begin{tabular}{|c|c|c|c|}
\hline $\begin{array}{c}\text { Flaw } \\
\text { Identifier }\end{array}$ & $\begin{array}{c}\text { Spanwise Location } \\
\text { [m from blade root }]\end{array}$ & $\begin{array}{c}\text { Blade } \\
\text { Surface }\end{array}$ & Flaw Type \\
\hline GL3 & 1.60 & Low Pressure & In-Plane Wave \\
\hline GL4 & 1.80 & Low Pressure & Porosity \\
\hline GL8 & 3.20 & Low Pressure & Porosity \\
\hline GL12 & 5.00 & Low Pressure & In-Plane Wave \\
\hline GL13 & 6.20 & Low Pressure & Out-Of-Plane Wave \\
\hline GL14 & 6.25 & Low Pressure & Out-Of-Plane Wave \\
\hline GH4 & 1.80 & High Pressure & Porosity \\
\hline GH9 & 3.75 & High Pressure & Out-Of-Plane Wave \\
\hline GH10 & 4.20 & High Pressure & In-Plane Wave \\
\hline GH11 & 4.70 & High Pressure & Out-Of-Plane Wave \\
\hline GH12 & 5.01 & High Pressure & In-Plane Wave \\
\hline GH13 & 6.20 & High Pressure & In-Plane Wave \\
\hline GH14 & 6.25 & High Pressure & In-Plane Wave \\
\hline
\end{tabular}




\section{Test Loads}

Figure 2 provides the characteristic flapwise bending moment distributions developed by SNL for the fiberglass spar cap and carbon fiber spar cap blades. The characteristic bending moment provided the initial estimate for the fatigue strength of the blade, and included knockdown factors introduced by the built-in flaws. The characteristic strength was based on a 250,000-cycle flapwise fatigue loading. The number of target test cycles was selected to test the blade to failure in a reasonable timeframe. During testing, target test moments and their respective cycle counts were modified based on updated information and results from completed load cases. The shape of the characteristic test bending moment is typical of flapwise bending moments used for wind turbine blade testing, with a second- to third-order polynomial used to describe the shape of the bending moment.

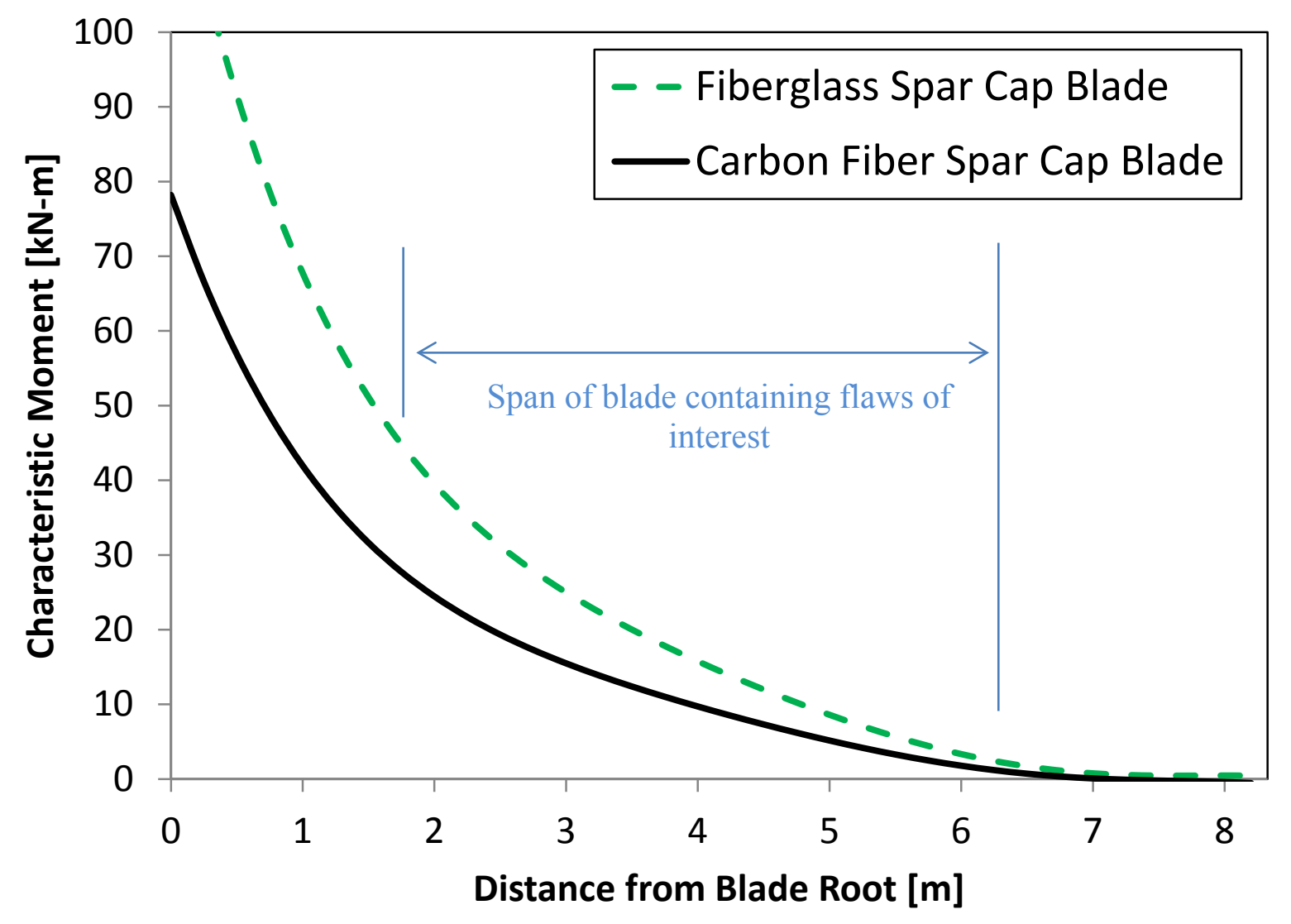

Figure 2. Characteristic test flapwise bending moments for fiberglass and carbon fiber spar cap blades

A primary consideration for developing the test loading was to apply a test load that would fatigue-test the greatest number of critical flaws to their expected lifetime. The quantity, ranked severity, and distribution of the flaws along the length of the spar cap required a phased approach to testing the blade. The general test configuration was similar to conventional methods used to test wind turbine blades. The root of the blade was cantilevered to a rigid test stand, and a test bending moment was introduced to the blade by applying a point-force with a hydraulic actuator; 
however, loading one area of the blade too aggressively might have resulted in a blade failure in a region nearer to the root that would have prevented testing of all areas and flaws of interest. To prevent unintended failures of flaws in the inboard regions of the blade early in the test, loads were first applied near the tip of the blade to test outboard regions of the blade, then the actuator was moved to a position closer to the root to test an inboard region.

The critical flaws were located near or in the low-pressure and high-pressure side spar caps. A flapwise fatigue test was selected because this loading orientation caused high loads and strains in the spar caps and flaws. Figure 3 is an image of a blade cross section. This image shows the location of the high and low-pressure spar caps, and identifies the coordinate system used for testing. Test loads were applied to the blade in the flapwise direction, perpendicular to the laboratory horizontal position. Positive flapwise bending moments (high-pressure side in tension) were applied by extending a hydraulic actuator. Loads were applied to the blade near the $32 \%$ chord position, roughly in line with the spar caps.

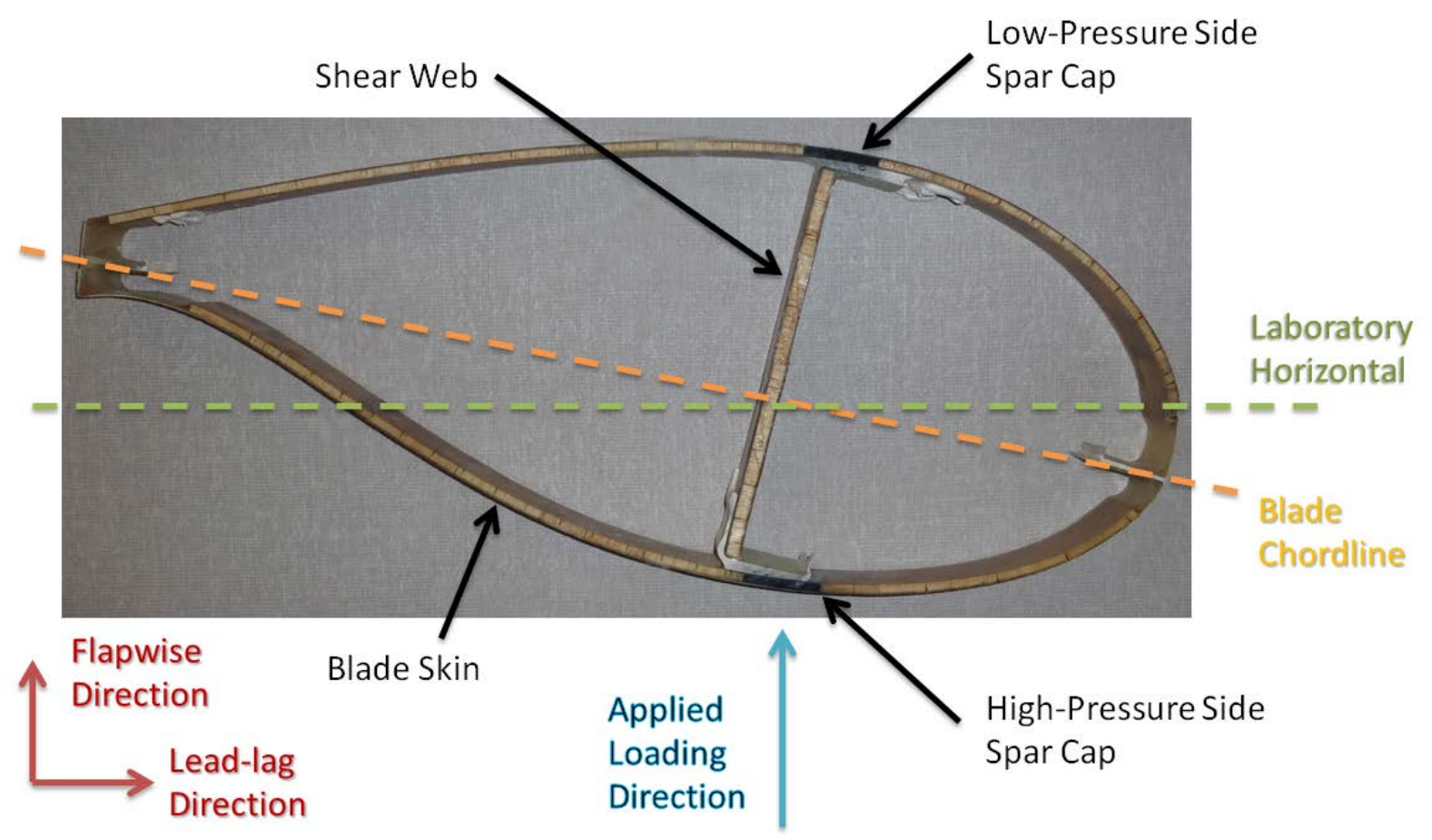

Figure 3. Blade cross section showing blade components and the test coordinate system. Photo by Scott Hughes, NREL 32523

The test loading was developed to provide a reasonable match of the characteristic bending moment along the blade span that contained critical flaws (on the blade span between $1.6 \mathrm{~m}$ and $6.3 \mathrm{~m}$ ). Three load application stations were used to test this span of the blade. The nominal load stations were $7 \mathrm{~m}, 6 \mathrm{~m}$, and $4.37 \mathrm{~m}$, as measured from the root of the blade. Loading the blade at a single station produces a linear bending moment from the root of the blade to the load introduction station. Load stations were modified during the course of the testing because of several factors discussed in the following sections. Figure 4 provides the target test bending moment and applied test bending moments for each of the three load cases. Each of the test 
moments were applied independently to test specific spans of the blade. Loading at the outboardspan load station of $7 \mathrm{~m}$ provided a test moment for blade spans from the $5.5-\mathrm{m}$ station to the 6.5-m station. Loads applied at the midspan load station of $6 \mathrm{~m}$ matched the characteristic bending moment distribution between blade spans $3 \mathrm{~m}$ to $5.5 \mathrm{~m}$ from the root of the blade. Loads applied at the inboard-span load station of $4.37 \mathrm{~m}$ were intended to match the target moment between the blade span between $1.6 \mathrm{~m}$ and $3 \mathrm{~m}$. The sequence of testing for each blade started with the application of the outboard-span load case, followed by applying the midspan load case, and concluded by applying loads to the inboard-span test region.
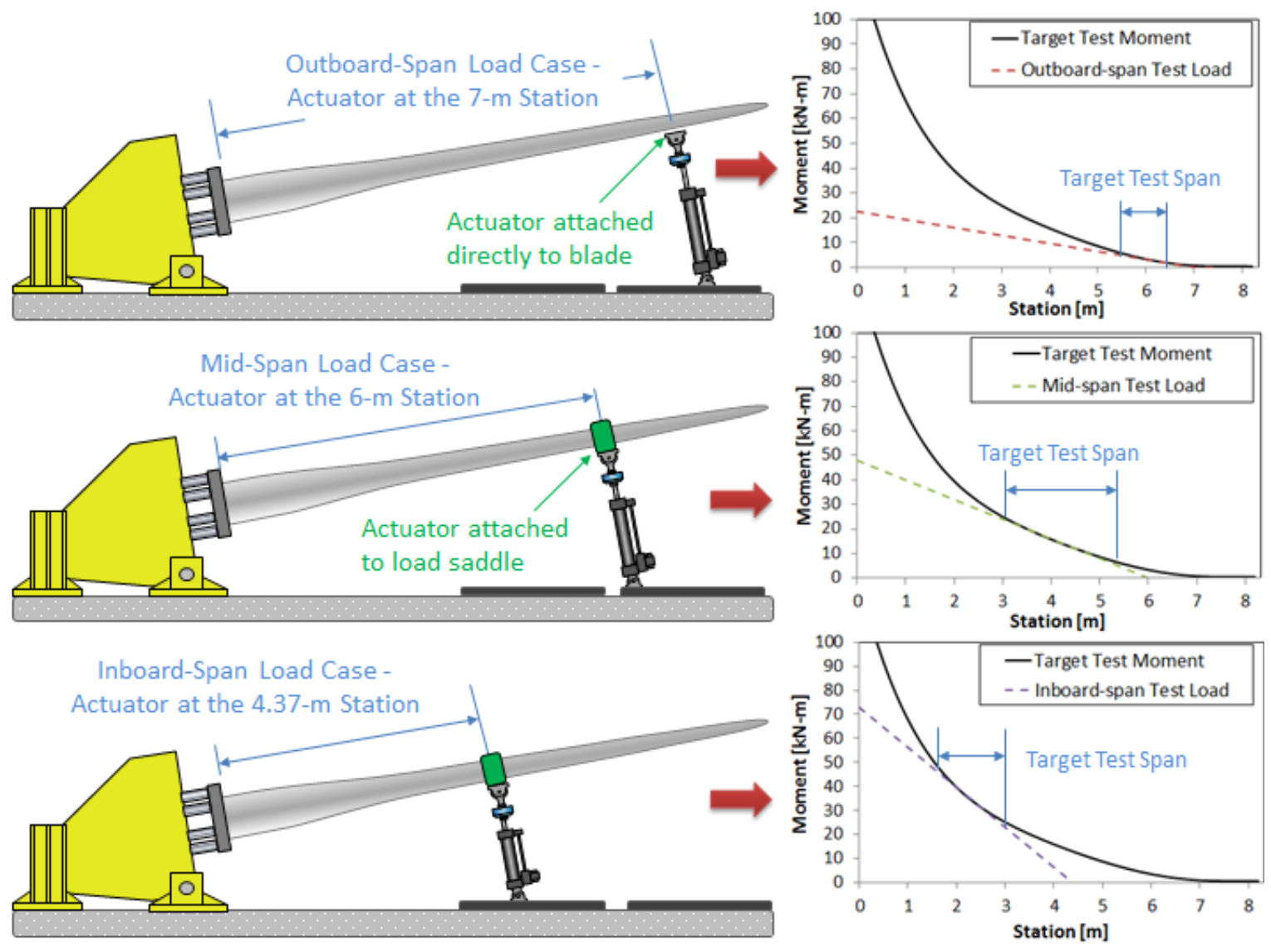
Figure 4. Mechanical setup and resulting test bending moments for outboard (top), midspan (middle), and inboard (bottom) load cases. IIlustration by Scott Hughes, NREL

For load cases applied at the 7-m station with higher load and displacement requirements, the required test displacement exceeded the actuator displacement capacity. To apply these high-load load cases, a load saddle and strut were attached to the blade and connected to the laboratory floor at the 6-m station. This measure reduced the actuator displacement required to achieve the target bending moment. Figure 5 shows the test setup with the blade clamped at the 6-m station; in this case the resulting bending moment is compared against the baseline target test moment. 

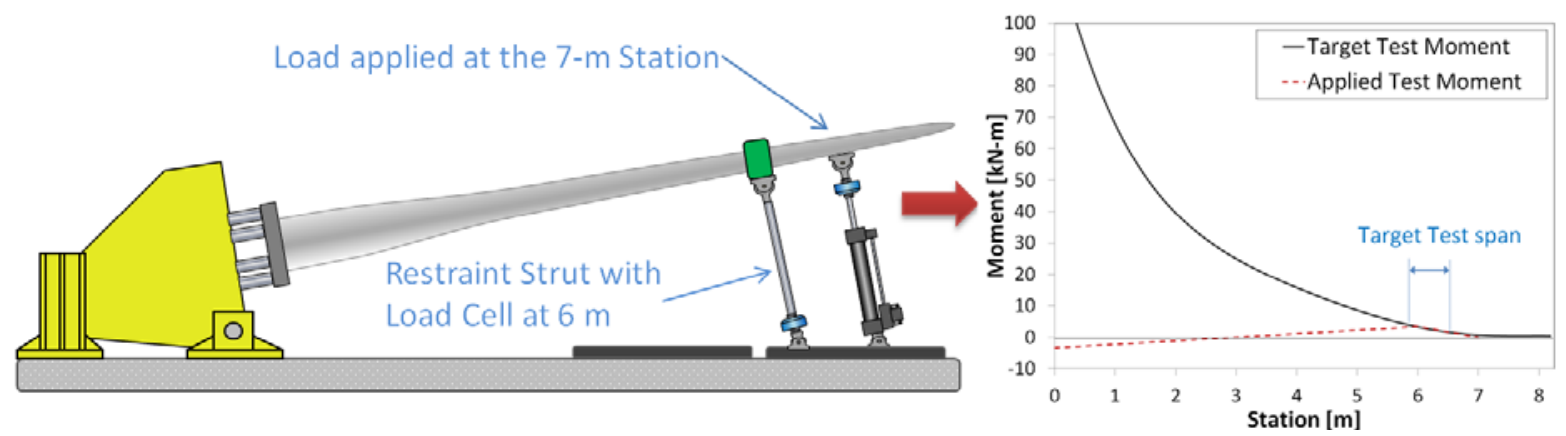

Figure 5. Setup and applied moment for load cases applied with strut at the 6-m station. IIlustration by Scott Hughes, NREL

For fatigue loading, a sinusoidal load was applied to the blade by a hydraulic actuator. Fatigue test loads were applied at an $\mathrm{r}$-ratio of $\mathrm{R}=0.1$. The $\mathrm{r}$-ratio is defined as the minimum load divided by the maximum load. For each fatigue load case, loads were applied in load blocks with each load block having a distinct maximum and minimum load. The number of cycles and load levels within a load block were determined by MSU. Figure 6 provides a generic representation of a load case, showing increasing-amplitude load blocks at an r-ratio of 0.1 . In the generic representation shown in Figure 6, loads are applied at a test frequency of 1 hertz $(\mathrm{Hz})$ (one test cycle per second), with load levels increasing for each load block while maintaining an r-ratio of $\mathrm{R}=0.1$.

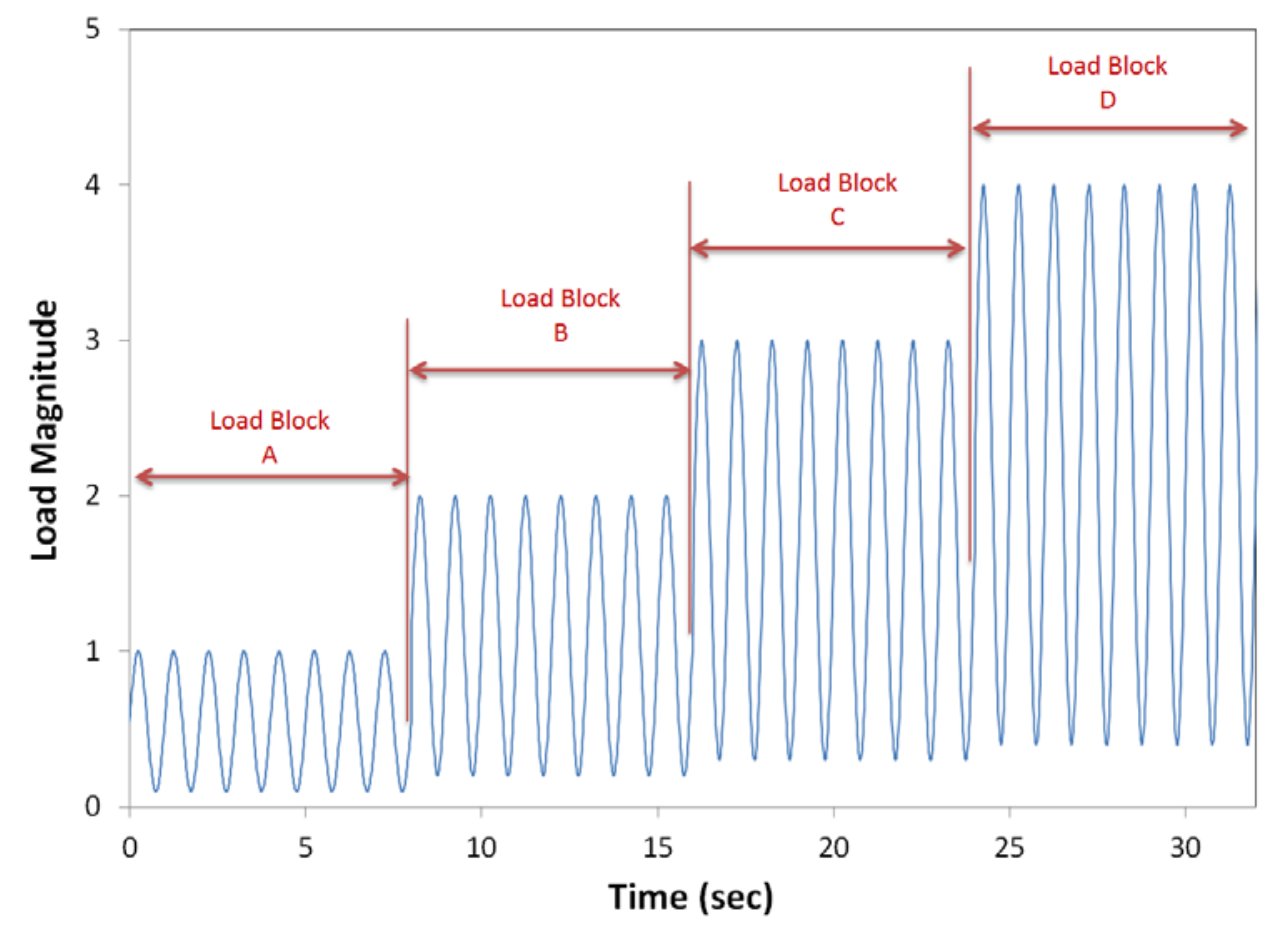

Figure 6. Fatigue load case generalization, depicting individual load blocks. Illustration by Scott Hughes, NREL 


\section{Test Setup}

Testing was performed inside the A-60 test facility at the NWTC. The blade was cantilevered to a test stand with an overturning moment capacity of 1.36 meganewton meters $(\mathrm{MN}-\mathrm{m})$. Figure 7 provides an illustration of the major mechanical test system components, including the test stand, adapter plate, hydraulic actuator, and load saddle. Both the fiberglass spar cap and carbon fiber spar cap blades were installed on the test stand with the high-pressure surface of the blade towards the laboratory floor. The blade was mounted to the test stand with the chordline at the 5$\mathrm{m}$ blade station parallel with the laboratory horizontal plane. The actuator applied loads in the flapwise direction. The inclination of the actuator in the spanwise direction was set such that the actuator load line of action was perpendicular to the deflected shape of the blade at the midpoint of the applied load range. This actuator position was chosen to minimize the introduction of secondary moments and spanwise forces created when the load line of action is not perpendicular to the span of the blade.

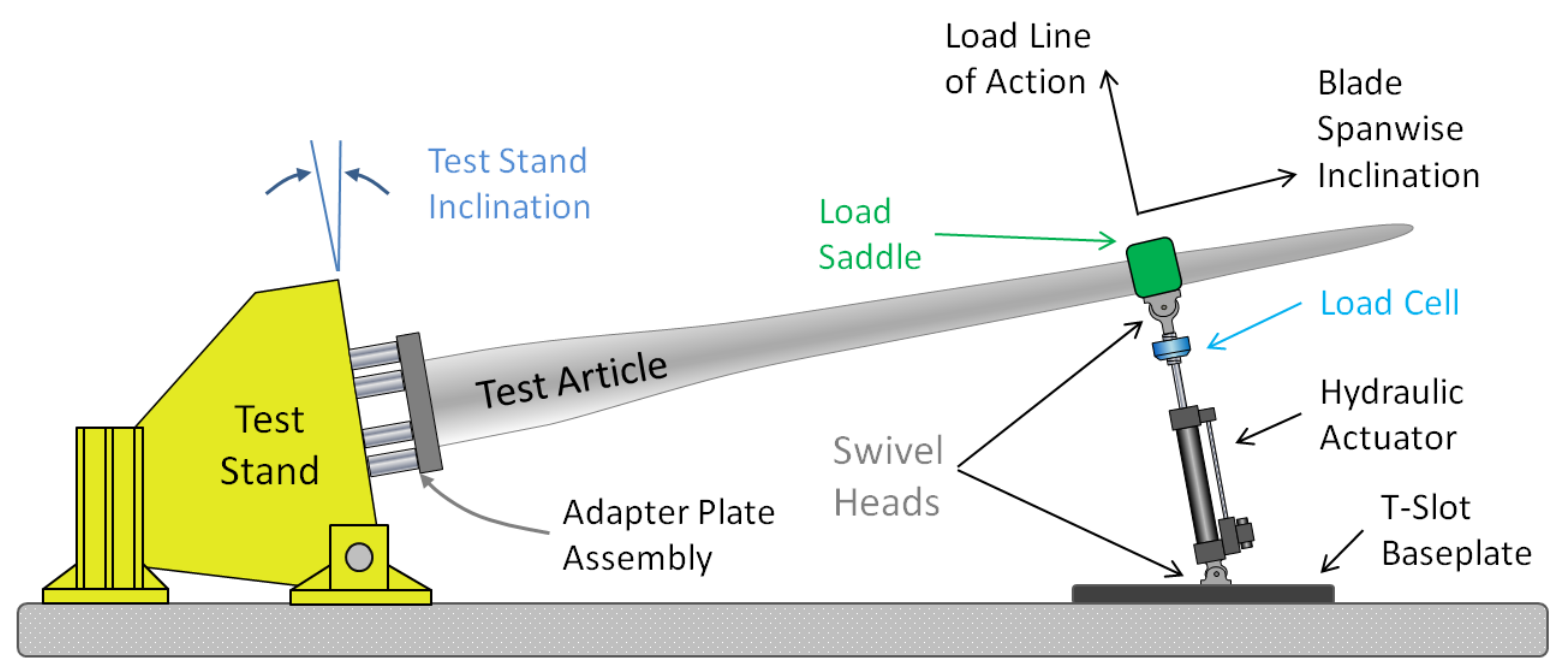

Figure 7. Mechanical elements of test setup. IIlustration by Scott Hughes, NREL

Blades were attached to the test stand through an adapter plate assembly. A 76-mm thick steel adapter plate was bolted to the root of the blade. The nominal bolt pattern of the blade root consisted of twenty-four 5/8-16 Unified National Fine studs positioned on a 504-mm bolt circle. The adapter plate was connected to the test stand using twenty 1-8 Unified National Course fasteners positioned on a 762-mm (30 inch nominal) bolt circle. The adapter plate was offset from the test stand face using 254-mm-long steel cylinders placed between the test stand face and adapter plate. This configuration allowed access for camera and sensor cables to the inside cavity of the blade. Figure 8 shows a photograph of the blade and adapter plate as mounted to the test stand. The test stand tilt angle was changed several times during the test program to accommodate different actuator heights and strokes required for the different load cases. 


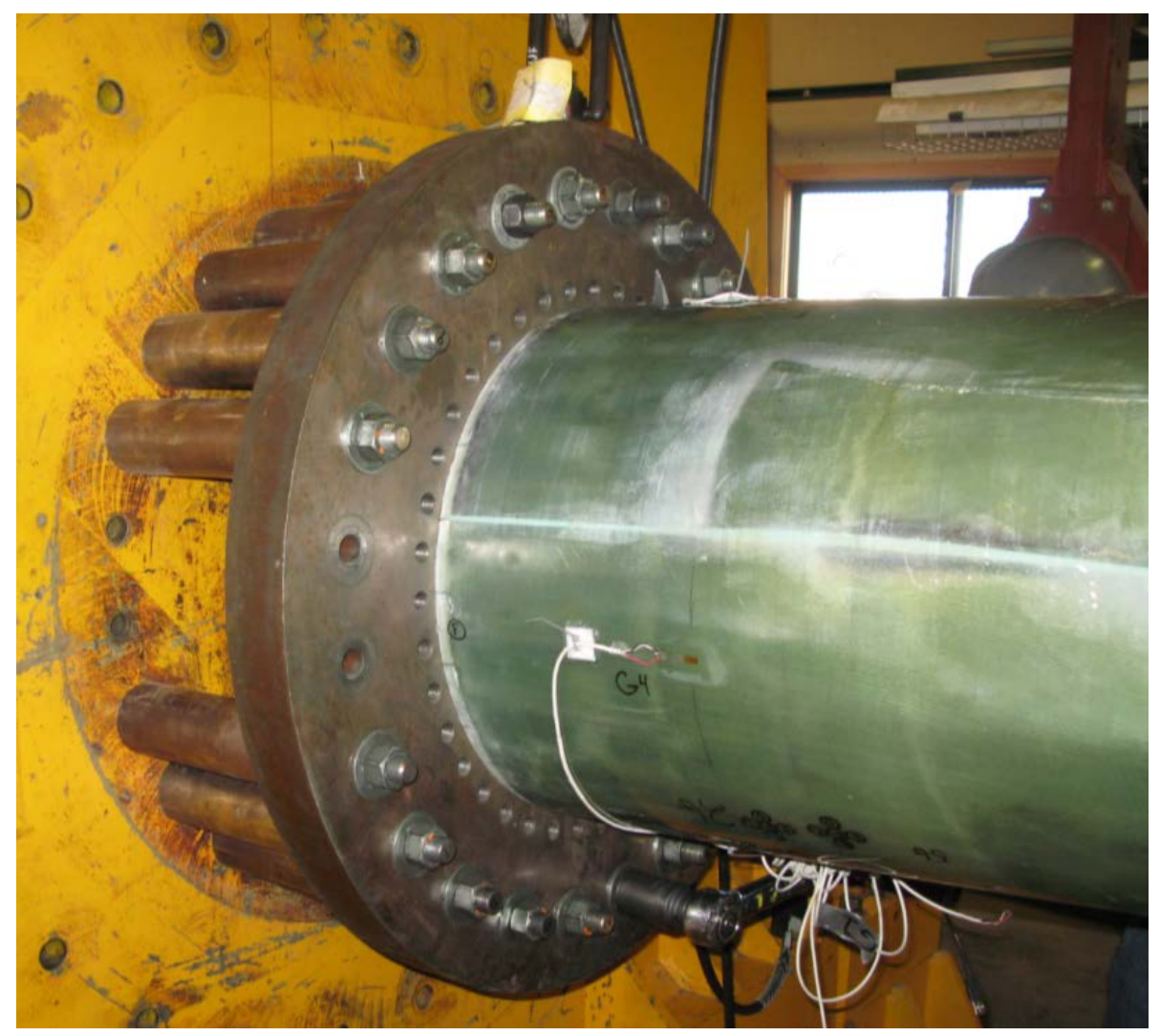

Figure 8. Photograph of the blade root to test stand fixture. Photo by Michael Desmond, NREL 32525

A hydraulic actuator was used to apply test loads to the blade. Two different actuators were used during testing because of different stroke and force requirements of each of the load cases. Load cases applied at the outer load stations of $6 \mathrm{~m}$ and $7 \mathrm{~m}$ required longer actuator strokes compared to load cases applied at the inboard load station. Load cases applied at the outboard and middle load stations used a hydraulic actuator with a stroke capacity of $760 \mathrm{~mm}$, and force capacity of $66.7 \mathrm{kN}$. Load cases at the inboard load station employed an actuator with a 510-mm stroke, and force capacity of $66.7 \mathrm{kN}$. The hydraulic actuators were controlled via a servo-hydraulic controller. The hydraulic test system operated at a working pressure of 20.6 megapascals (MPa).

Actuator control was based on displacement feedback measured by a linear variable differential transformer (LVDT) displacement sensor mounted inside of the actuator. Displacement was used for actuator control, versus force-feedback, because inertial loading from the blade and actuator piston distorts the actual load applied to the blade (Musial and Allread 1993). Actuator displacements corresponding to target loads were determined through periodic application of quasi-static (very slow) loads, applying loads slowly removes inertial effects from the load measurement. Quasi-static actuator displacements were mapped to the applied load. During fatigue test operation, the actuator was controlled to apply a sinusoidal load profile between the maximum and minimum displacements corresponding to the maximum and minimum load targets. Figure 9 shows a photograph of the actuator attached to the blade. 


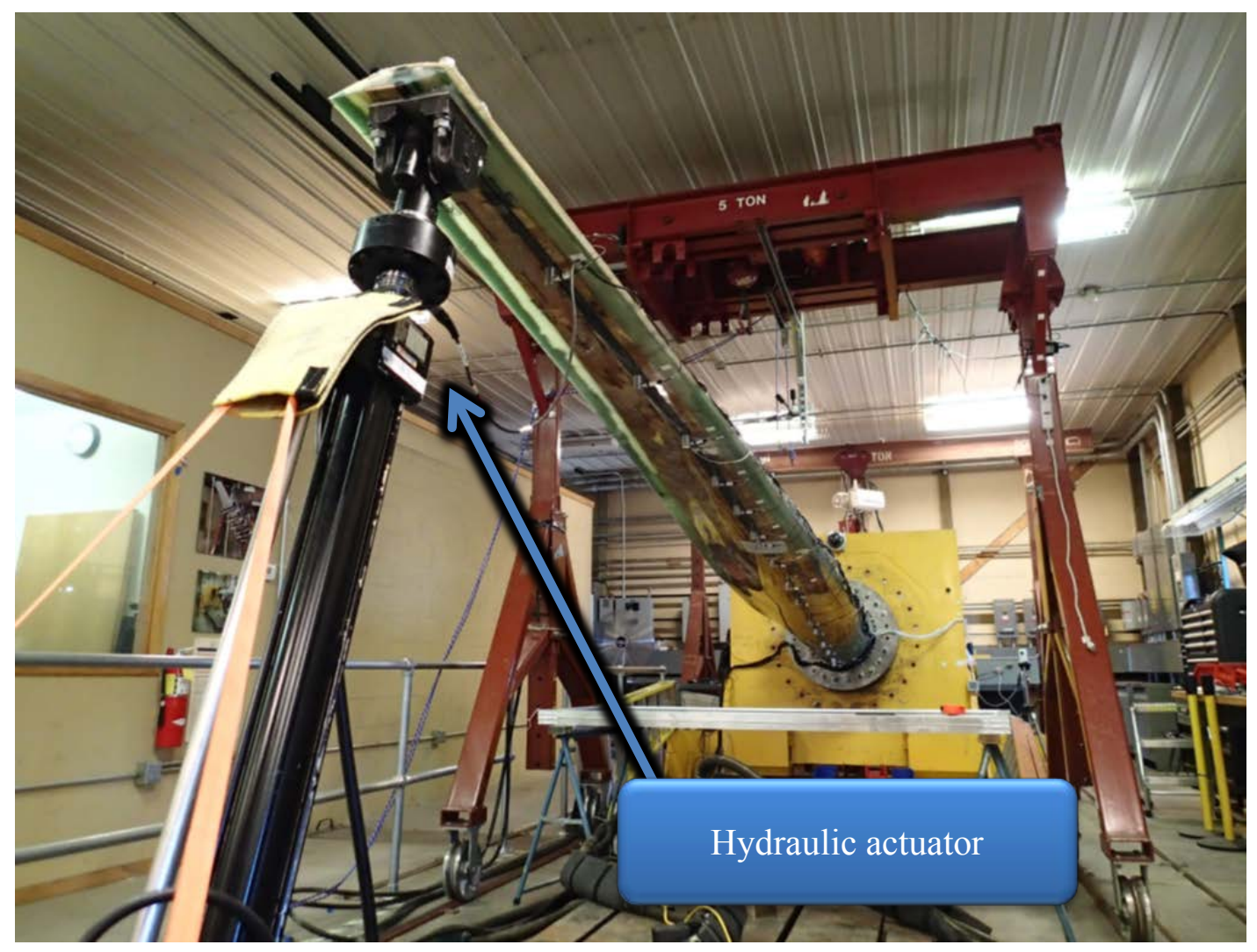

Figure 9. Test setup for loading the carbon spar cap blade at the 7-m station. Photo by Michael Desmond, NREL 32526

The actuator assembly includes the actuator, load cell, and swivel heads mounted to each end of the actuator assembly. The load cell measured the load applied to the blade by the hydraulic actuator. Swivel heads provide a rotation degree of freedom to each end of the actuator, allowing free rotation (with a small amount of friction) of the blade as the blade deflects during loading.

The actuator was connected to the blade by one of two methods, direct connection, or through a load saddle. Figure 10 provides photographs of the two attachment methods. Load cases applied at the 7-m station used a direct connection between the blade and the actuator swivel head. The advantage of the direct connection method is a reduction in the distance between the blade and the center of the swivel head. Reducing this dimension minimizes secondary moments and spanwise forces caused by misalignment between the actuator and blade (IEC 2002). A drawback of the direct connection method is it typically requires the inside of the blade to be reinforced with material (plywood and epoxy) to evenly distribute the load to the blade and prevent crushing of the blade skins or shear web. Direct connection also requires that holes are drilled on both sides of the spar cap and shear web to preload the connection. Load saddles were fabricated for use at the midspan and inboard span load stations of $4.37 \mathrm{~m}$ and $6 \mathrm{~m}$. The load saddles were constructed using wood forms surrounded by steel frames. The wood forms consisted of epoxied microlams that were cut to match the station airfoil profile. A thin strip of rubber placed between the wood form and the blade surface helped distribute the load from the saddle to the blade surface. The load saddle wood forms were approximately $130 \mathrm{~mm}$ thick in the spanwise direction. Steel frames were fabricated around the wood forms and secured the load 
saddle to the blade. The actuator assembly mounted to the steel frame of the saddle on the highpressure side of the blade.

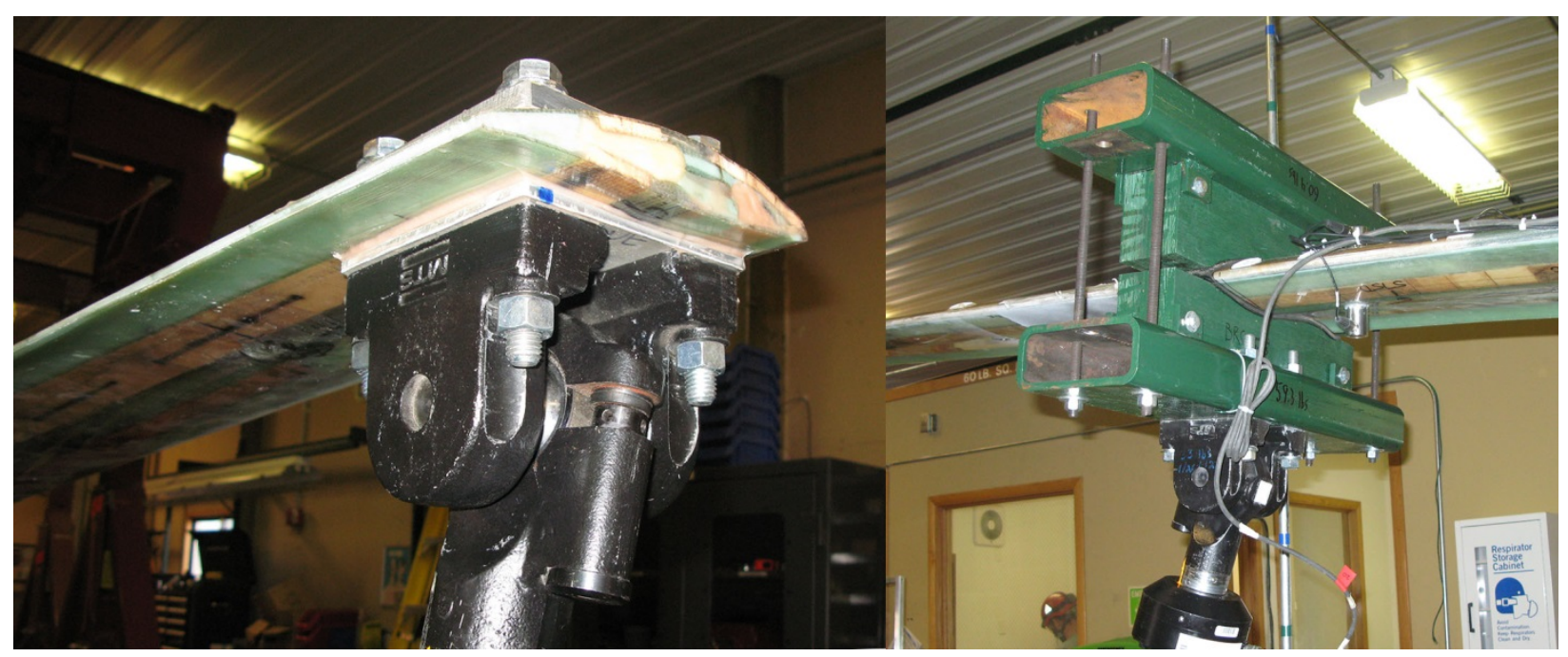

Figure 10. Actuator to blade attachment methods: direct attachment (left) and load saddle (right). Photo by Michael Desmond, NREL 32517

For high amplitude load blocks applied at the 7-m station, the required test displacements exceeded the displacement capacity of the actuator. To enable reaching the target loads and moments in these high amplitude load blocks, the blade was clamped with a load saddle at the 6$\mathrm{m}$ station. Vertical motion of the 6-m saddle was restrained by connecting a strut attached to the saddle and to the laboratory floor. Swivel heads were installed at each end of the strut. This configuration reduced the actuator displacement necessary to reach higher test moments. Figure 11 shows a photograph of this configuration. 


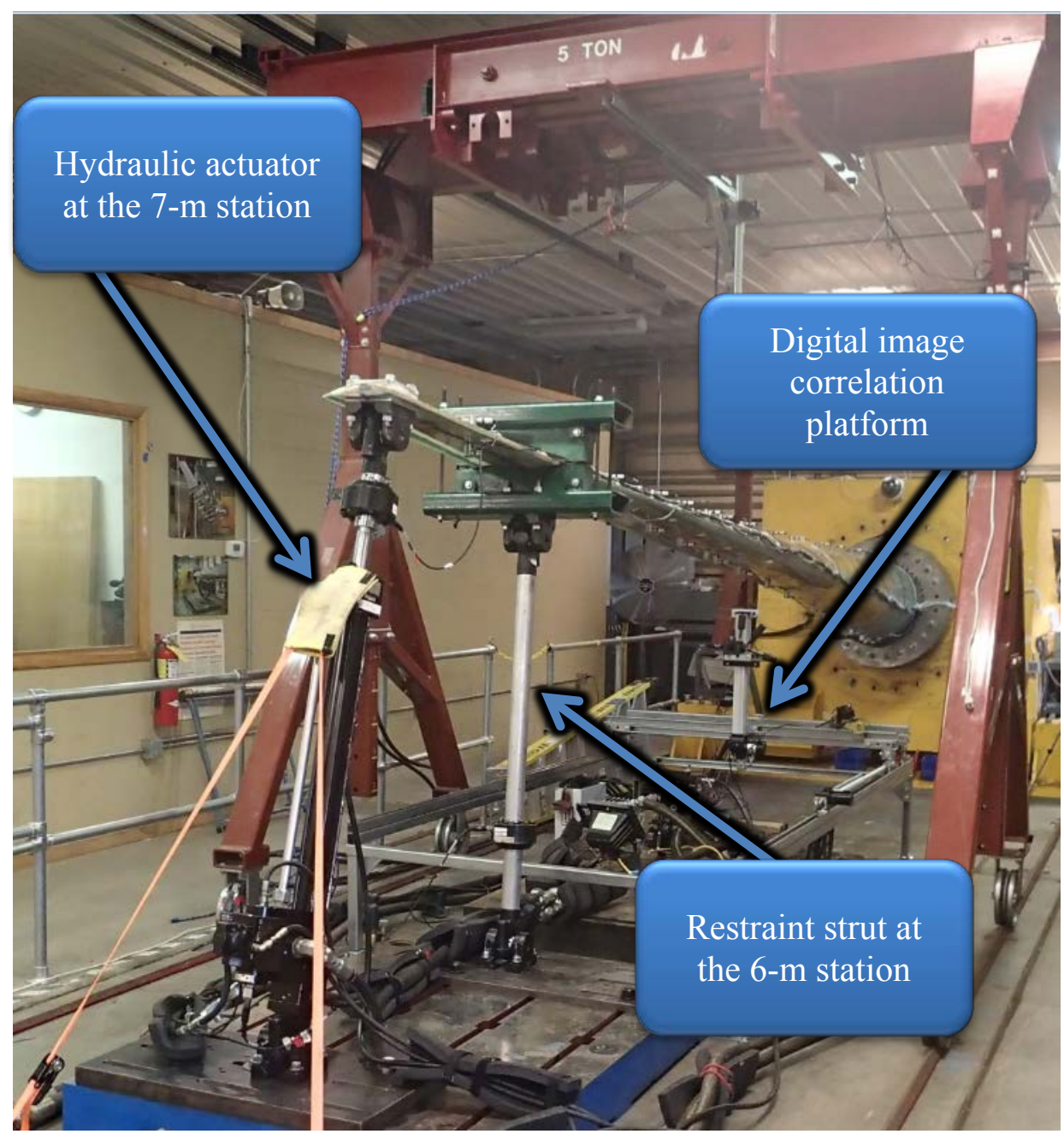

Figure 11. Test setup for actuator at the 7-m station and restraint strut at the 6-m station. Photo by Michael Desmond, NREL 32518 


\section{Data Acquisition}

Several types of sensors and measurement systems were used during testing. A typical suite of sensors used for wind turbine blade testing was employed, including measurement of test loads, test displacements, strain measurements, and laboratory temperature and humidity (IEC 2002). In addition to the set of basic sensors, the testing team employed acoustic emission, full-field strain measurement using digital image correlation (DIC) and thermography systems. SNL staff also conducted a nondestructive evaluation of the blade using ultrasonic systems.

A DIC system provided and operated by MSU was used to capture full-field images of mechanical strains at critical flaw locations. Obtaining full-field strain visualization of areas of the blade with embedded flaws was given priority over other sensing systems, keeping the areas at and near flaws clear of surface-mounted sensors and cabling. DIC has been used increasingly for its ability to measure full-field effects of defects in wind turbine blade testing (Niezrecki 2014). The blade surface at critical flaw locations was painted and speckled to create the optical surface needed for the DIC imaging. DIC images were taken throughout testing, capturing strain fields in various loading conditions, including unloaded states (zero strain) and when the target test loads and moments were applied (high strain). The distance and position of the DIC camera relative to the blade was important for accurate strain measurements. Remotely actuated DIC positioning systems were developed to allow a test operator to move the position of the camera as the blade deflected from the application of the test loads. To make images of the low-pressure surface, the DIC camera was mounted and positioned with linear electric actuators attached to the highbay gantry crane. On the high-pressure side, the DIC camera was mounted to a platform capable of moving the DIC camera in the spanwise direction, and within a certain distance to blade surface. The remotely actuated positioning platforms and mounts are shown in Figure 11. Figure 12 shows areas of the blade patterned for DIC imaging. 


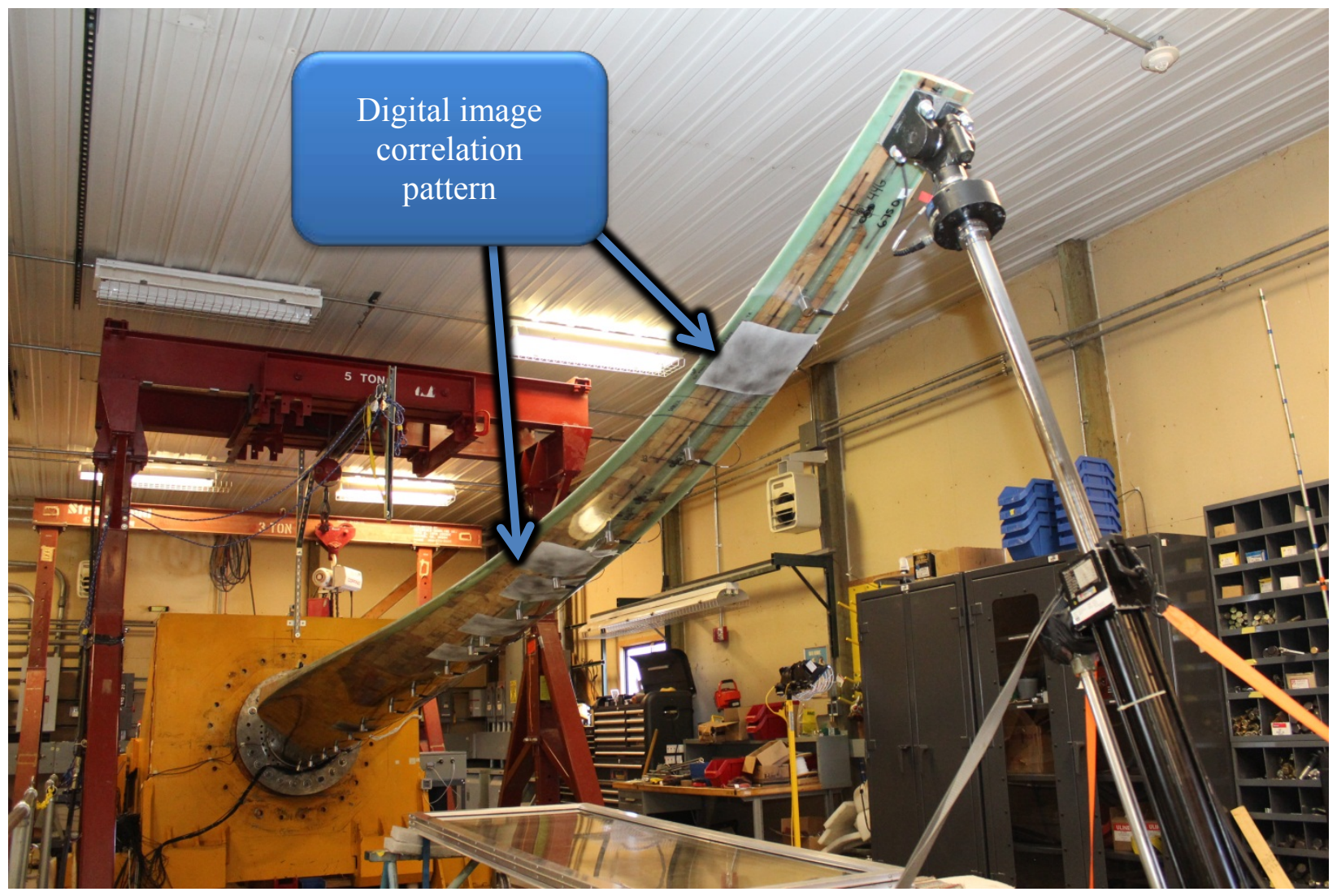

Figure 12. Digital image correlation imaging pattern painted on the blade surface over areas containing flaws.

Photo by Scott Hughes, NREL 32519

An acoustic emission (AE) system was used for surface acoustic emission data collection. Al Beattie, a subcontractor with SNL, calibrated and configured the AE system to record the energy and location (time and space) of acoustic events within the composite structure of the blade. Thirty-two AE sensors were mounted to the outside surface of the blade on both the highpressure and low-pressure surfaces. The sensors were centered on the width of the spar cap in the chordwise direction. Figure 13 shows AE sensors mounted on the low-pressure surface of the blade. AE hits were recorded when the output from three AE sensors' neighboring flaw location registered amplitudes of at least 50 decibels $(\mathrm{dB})$ and a duration less than 50 microseconds. These front-end filter settings are similar to settings used for previous AE tests conducted by SNL and NREL (Beattie 2013a). 


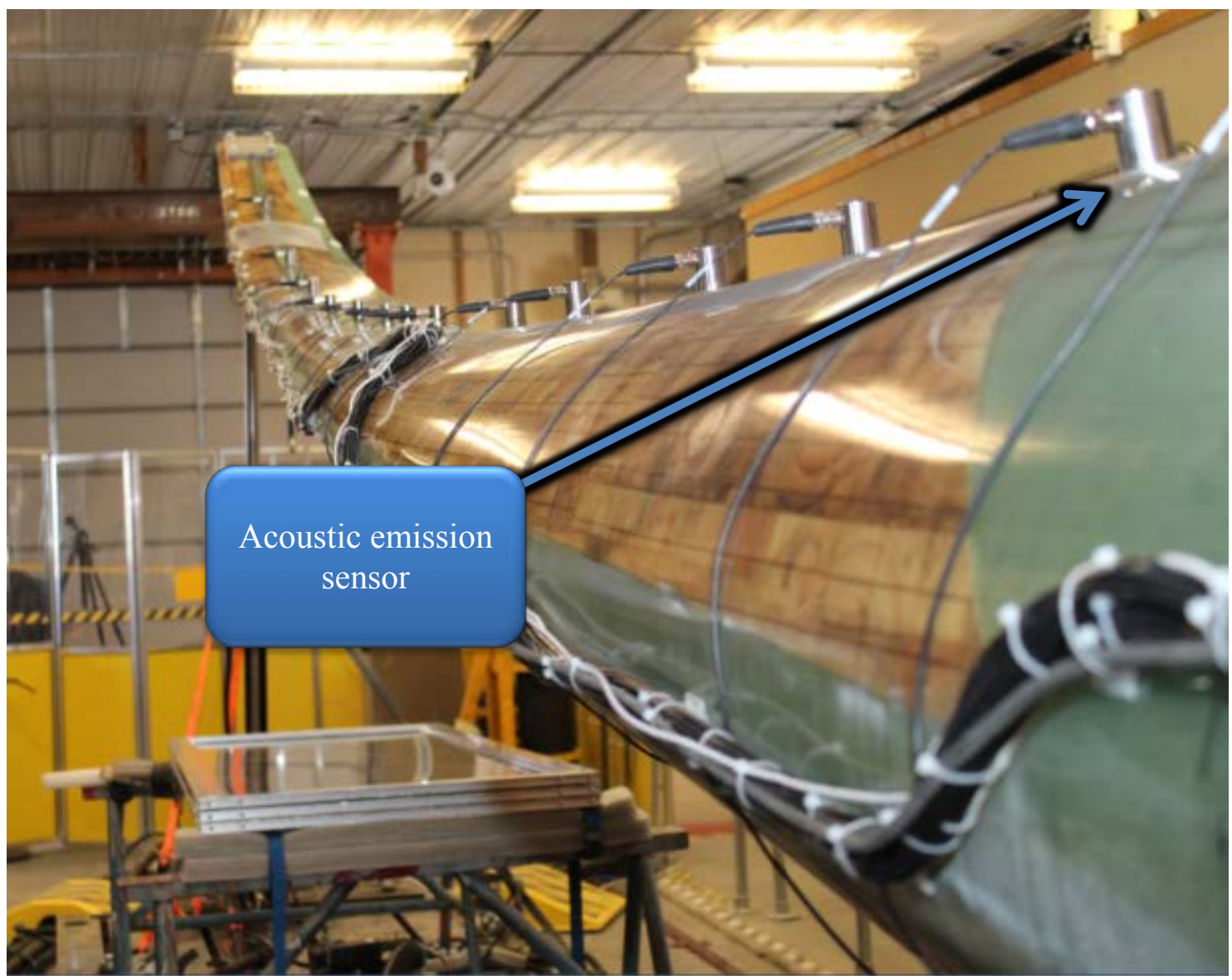

Figure 13. Acoustic emission sensors mounted to the low-pressure surface of the blade. Photo by Scott Hughes, NREL 32520

A FLIR SC-640 thermal camera was used to measure the temperature of the surface of the blade. Areas experiencing progressive damage are likely to have higher surface temperatures. Images were taken at various times during testing.

A limited number of resistance-type strain gages were applied to the blade. Resistance strain gages were used to measure the strain at a specific point on the blade. Single-element 350-ohm gages were used. Resistance-type strain gages were located outside of the critical flaw areas to allow unobstructed areas for the DIC strain imaging. The gages were installed on the blade to measure strains in the spanwise direction, in line with, and centered on the spar cap. Resistancetype gage locations on the fiberglass spar cap blade include gages at the $3.5-\mathrm{m}$ and $5.25-\mathrm{m}$ stations on both the high-pressure and low-pressure surfaces. On the carbon fiber spar cap blade, high-pressure side gages were located at the $2.75-\mathrm{m}, 3.7-\mathrm{m}$, and $5.25-\mathrm{m}$ stations. On the lowpressure side of the carbon spar cap blade, resistance-type gages were located at the $2.75-\mathrm{m}$, 3.75-m, and 5.25-m stations.

Applied test loads were measured with a load cell located between the blade and the actuator. A load cell was also installed inline with the strut at the 6-m station. Deflection of the blade caused by the applied test loads was measured at the actuator load introduction station. An LVDT mounted inside of the actuator was used to measure deflection. Loads, actuator displacements, 
resistance-type strains, and laboratory temperature and humidity were recorded during testing with the NREL Ethercat Data Acquisition System (EDAS). The EDAS is based on National Instruments (NI) Ethercat PXI data acquisition hardware combined with NI LabVIEW software that is custom-developed for structural testing. All channels were scanned at 1,000 Hz and recorded as peak-valley pairs for each fatigue cycle. 


\section{Testing the Fiberglass Spar Cap Blade}

The first load case was testing the outboard-span of the fiberglass spar cap blade, with the actuator applying test loads at the 7-m station. Loads were applied in blocks and distinct maximum and minimum loads were documented in the test report (Desmond 2014). The first load block applied a cyclic load with a maximum load of $3.8 \mathrm{kN}$ and a minimum load of 0.38 kN. Six distinct load blocks encompassing 191,450 test cycles were applied; the final load block applied a maximum cyclic load of $6.4 \mathrm{kN}$ and a minimum load of $0.64 \mathrm{kN}$. The blade was clamped at the 6-m station for several load blocks because the required test displacement exceeded the displacement capacity of the actuator. Most load blocks were applied at a test frequency of $1 \mathrm{~Hz}$. Fatigue loads were applied to the blade until a blade failure occurred at the 6.2-m station, on the low-pressure surface of the blade. Figure 14 shows the test bending moment range applied to the $6.2-\mathrm{m}$ station. Because of a data acquisition system software error, data were not recorded between cycle 179,777 and the failure cycle of 191,450. After reviewing load and displacement data collected by the hydraulic controller, it was determined that target test displacements remained constant during the period when data were not stored on the data acquisition system.

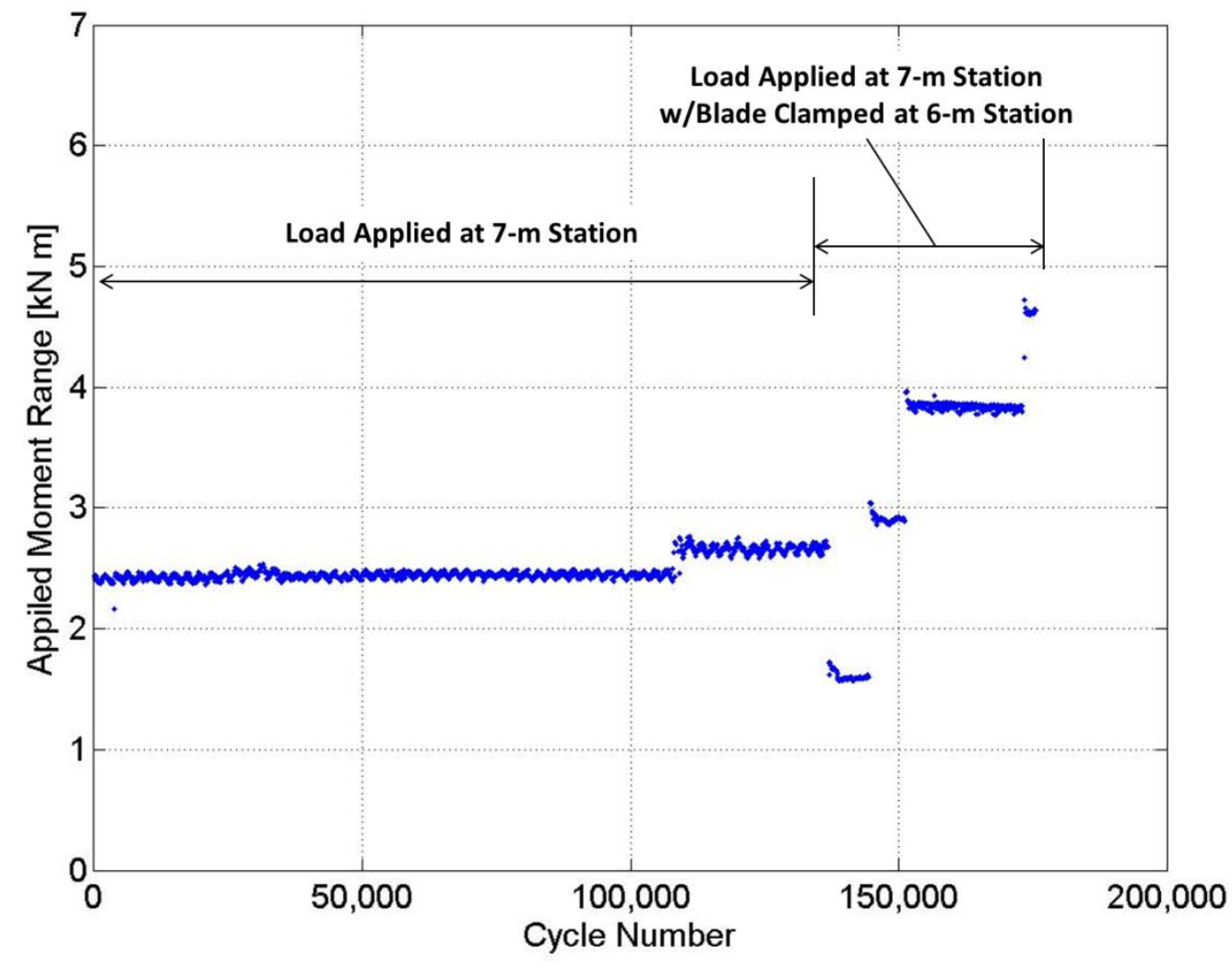

Figure 14. Moment range versus cycle applied to the 6.2-m station, fiberglass spar cap blade

Linear beam-bending equations were used to calculate applied bending moments given in this document. The applied moment range at a given blade station was calculated using either Eq. 1 or Eq. 2 below. Eq. 1 was used to calculate the applied moment range for load cases where only 
the actuator was applying a force to the blade, or when the station being evaluated was outboard of the restraint strut. Eq. 2 was used when the restraint strut was attached to the blade, and the station where the moment was evaluated was inboard of the restraint strut. Forces shown in Eq. 1 and 2 were measured by load cells attached to the actuator and restraint strut. The influence of dynamic effects and test geometry described in the Test Setup Section are not included in these calculations.

$$
\begin{aligned}
& M_{O S}=\Delta F \cdot\left(d_{\text {act }}-x\right) \\
& M_{I S}=\Delta F \cdot\left(d_{\text {act }}-x\right)-\Delta R \cdot\left(d_{\text {strut }}-x\right) \\
& \Delta F=F_{\text {max }}-F_{\text {min }} \\
& \Delta R=R_{\text {max }}-R_{\text {min }}
\end{aligned}
$$

where:

$$
\begin{array}{ll}
M_{O S} & =\text { Applied moment range outboard of restraint strut }[\mathrm{kN}-\mathrm{m}] \\
M_{I S} & =\text { Applied moment range inboard of restraint strut }[\mathrm{kN}-\mathrm{m}] \\
\Delta F & =\text { Actuator force range for an individual test cycle }[\mathrm{kN}] \\
\Delta R & =\text { Restraint strut force range for an individual test cycle }[\mathrm{kN}] \\
d_{\text {strut }} & =\text { Distance from blade root to the restraint strut }[\mathrm{m}] \\
d_{\text {act }} & =\text { Distance from blade root to actuator [m] } \\
x & =\text { Distance from blade root to measurement station }[\mathrm{m}] .
\end{array}
$$

Figure 15 is a photograph of the failure region on the low-pressure surface at the 6.2-m station. The surface at this station had been patterned for DIC imaging. No destructive post-mortem inspections were performed following failures, allowing possible future coupon testing of properties. The failure location of $6.2 \mathrm{~m}$ coincides with the location of an out-of-plane wave in the spar cap. 


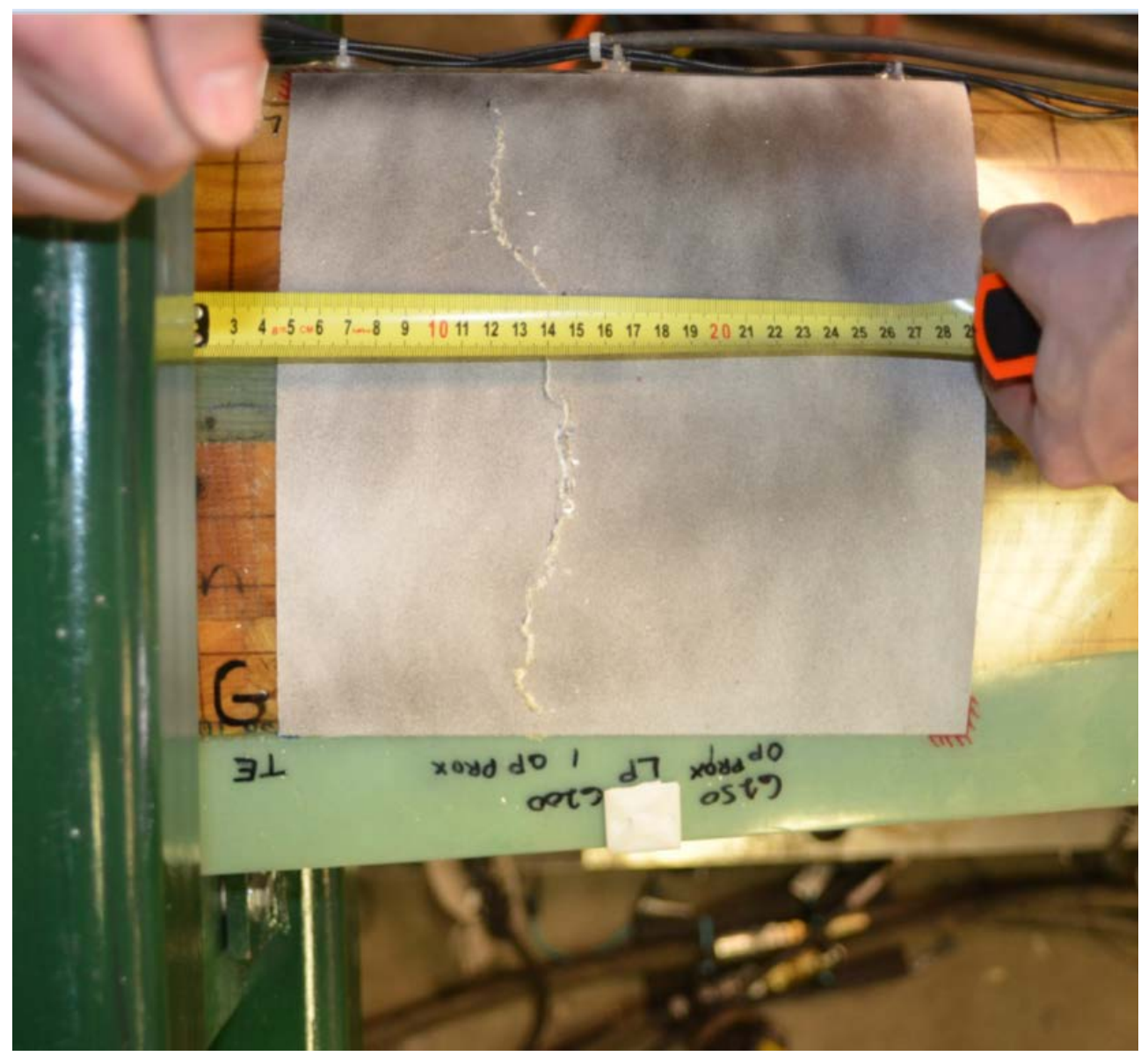

Figure 15. Fiberglass spar cap blade failure area at the 6.2-m station, low-pressure surface. Photo by Mike Jenks, NREL 32521

Following the blade failure at the 6.2-m station, the test was configured to apply the midspan load case with a hydraulic actuator applying loads at the 6-m station. This load case focused on testing the blade span between the 3-m and 5.5-m stations. The blade tip was cut off outboard of the saddle at the $6.1-\mathrm{m}$ station. The blade tip was removed to reduce the likelihood the damaged area outboard of the actuator at the $6.2-\mathrm{m}$ station would be subjected to additional damage that might obscure any future post-mortem inspections of the area. Loads were applied in load blocks with increasing maximum and minimum loads, with each load block having an r-ratio of $\mathrm{R}=0.1$. The initial load block had a maximum load of $6.7 \mathrm{kN}$ and a minimum cyclic load of $0.7 \mathrm{kN}$; loads during the final load block were $12.9 \mathrm{kN}$ maximum and $1.3 \mathrm{kN}$ minimum. Test loads were applied at frequencies between 0.5 and $0.75 \mathrm{~Hz}$. A total of 238,521 cycles were applied during the midspan load case at the 6-m station (429,971 total test cycles) when the blade catastrophically failed at the $3.75-\mathrm{m}$ station on the high-pressure side. Figure 16 shows the test bending moment range applied to the $3.75-\mathrm{m}$ station. Data presented include both bending moments applied during the outboard-span load case at the 7-m station, and loads applied during the midspan load case, with loads applied at the 6-m station. 


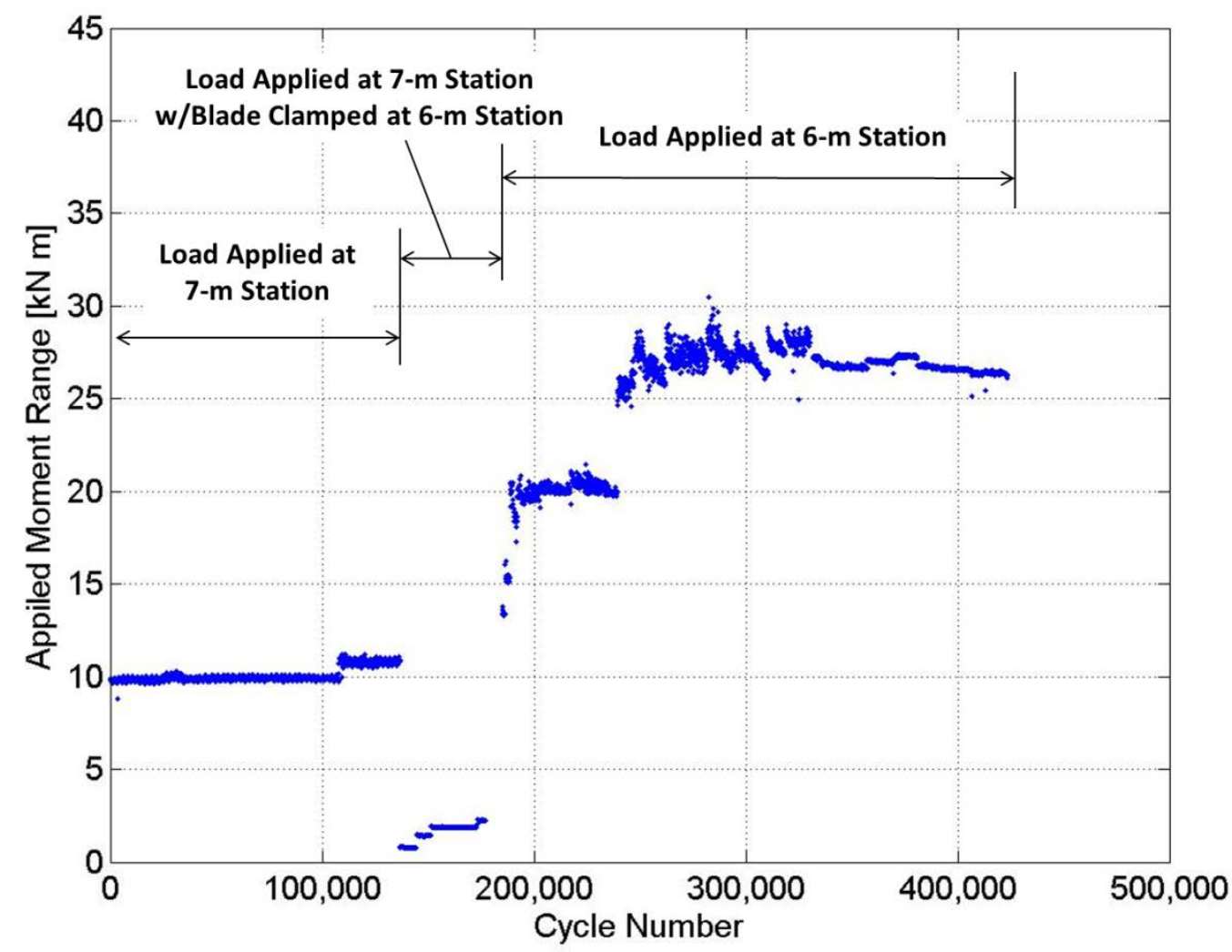

Figure 16. Moment range versus cycle at the $3.75-\mathrm{m}$ station, fiberglass spar cap blade

Blade failure occurred at the 3.75-m station on the high-pressure side. An out-of-plane wave flaw was built into the blade at this location. Prior to the final failure, increased AE activity along with changing strain gradients observed by the DIC system at the $3.75-\mathrm{m}$ station warranted a closer inspection of the region. The DIC pattern was removed from the surface of the blade to reveal the features of the damage area. Figure 17 shows the damage area with the DIC pattern sanded from the blade. Matrix (epoxy) cracking is visible across the entire width of the spar cap, with light-colored laminate radiating from the cracks. Light-colored regions in this case are likely caused by delaminations within the spar cap laminate. The final failure at this station was a catastrophic failure of the entire high-pressure skin shown in Figure 18, with the high-pressure skin spanning the entire chord length from the leading edge to the trailing edge. 


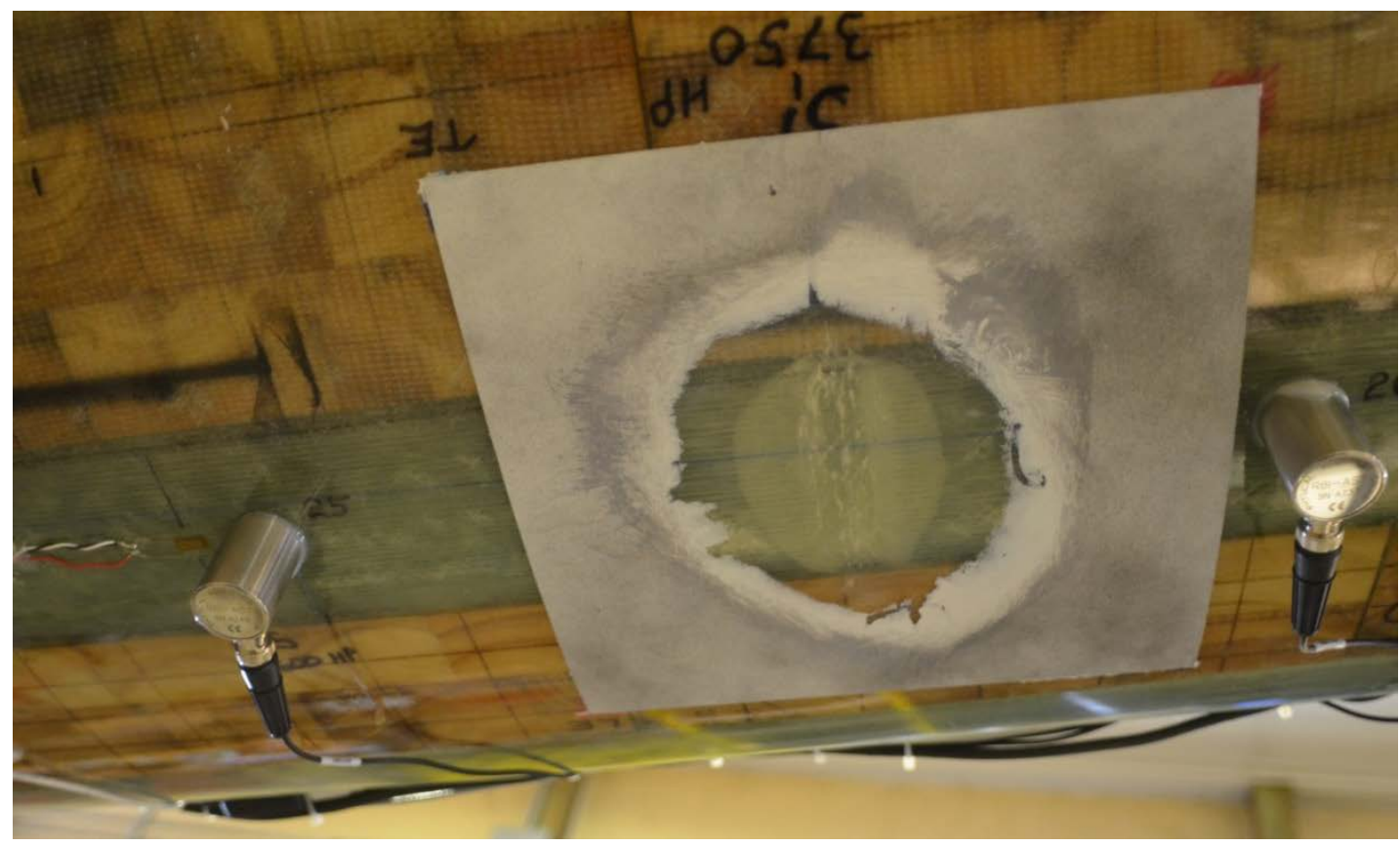

Figure 17. Fiberglass spar cap blade, high-pressure side damage area at the $3.75-\mathrm{m}$ station prior to catastrophic failure.

Photo by Michael Desmond, NREL 32522

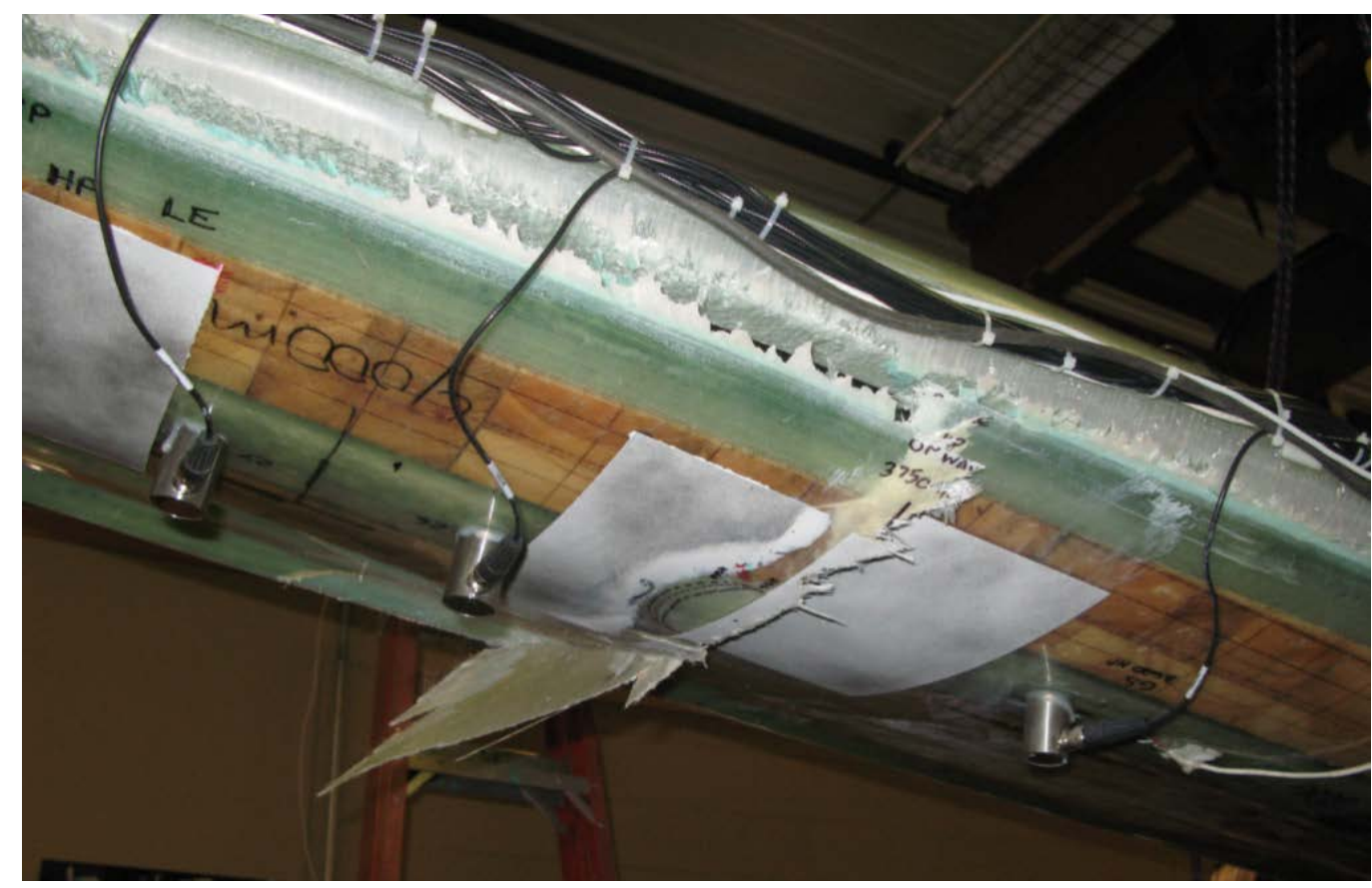

Figure 18. Fiberglass spar cap blade, high-pressure side catastrophic failure at the 3.75-m station. Photo by Michael Desmond, NREL 32524

The blade tip was cut off at the 3.6-m station for the inboard-span load case, with loads applied at the $3.5-\mathrm{m}$ station. The $3.5-\mathrm{m}$ station was not one of the original load points, because the original plan called for the inboard-span load to be applied at the 4.37-m station. Because the 
blade failed during the midspan loading at the 3.75-m station, using an inboard-span load station of $3.5-\mathrm{m}$ was the best alternative (i.e., it was the nearest inboard station from the previous failure location). The actuator was directly connected to the blade for this loading, with the internal cavity of the blade at the 3.5-m station reinforced with plywood and epoxy. In the chordwise direction, the actuator was oriented perpendicular to the local chord of the blade. Increasing amplitude load blocks were again applied to the blade; the first load block applied cyclic loads with a maximum of $8.9 \mathrm{kN}$ and minimum of $0.9 \mathrm{kN}$, the final load block applied cyclic loads of $44.5 \mathrm{kN}$ and $4.4 \mathrm{kN}$. A total of 27,724 cycles (457,695 total test cycles) were applied at the $3.5-\mathrm{m}$ station. Test frequencies between 0.5 and $0.75 \mathrm{~Hz}$ were used for this load case. The test was stopped because team members observed matrix cracking and probable delaminations on the high-pressure surface at the $1.2-\mathrm{m}$ station. This location corresponds to the location of the transition between the spar cap and root build-up laminate (the laminate thickness around the circumference of the blade increases near the root). There were no intentional flaws built into the blade at this location. Figure 19 provides a photograph of the damage area at the 1.2-m station.

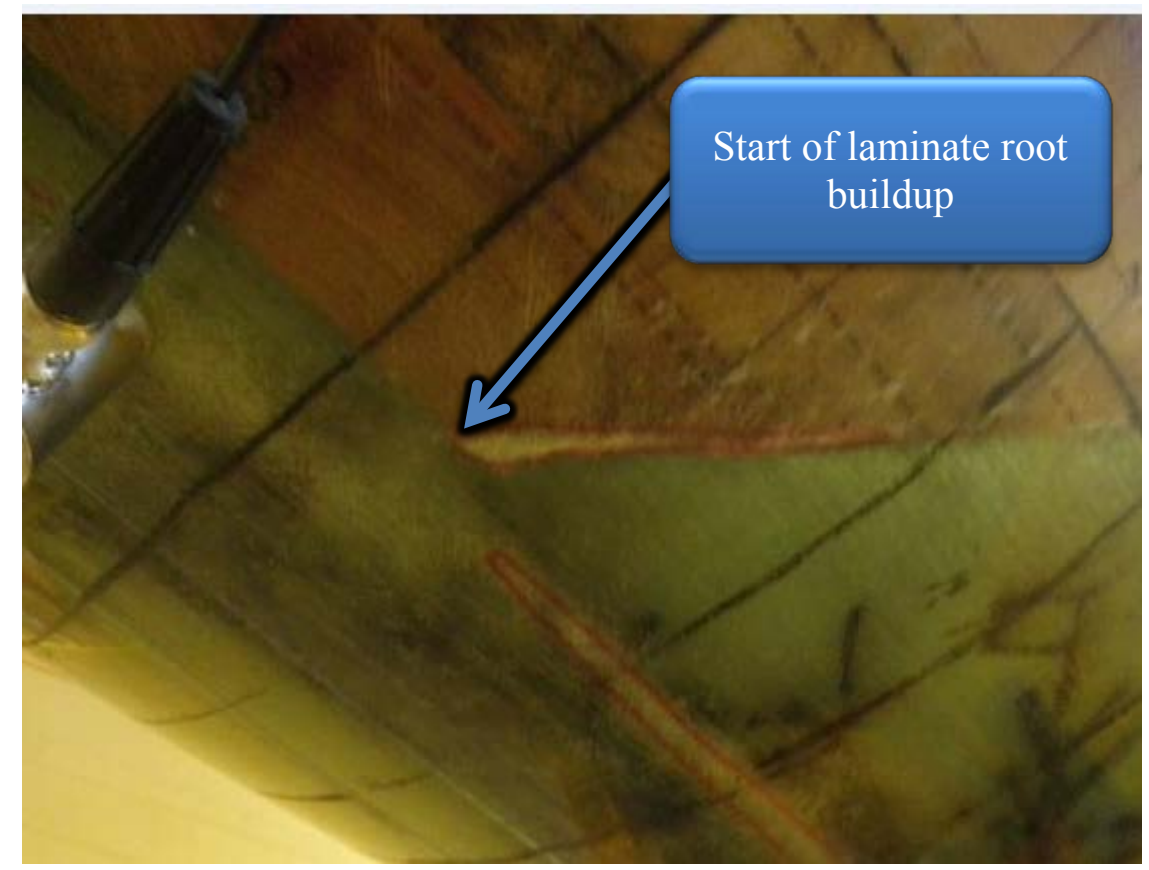

Figure 19. Fiberglass spar cap blade, damage area at the 1.2-m station on the high-pressure surface.

Photo by Michael Desmond, NREL 32527

A convenient way to express an equivalent constant amplitude load applied to a test article subjected to different load levels is by using a damage equivalent load (DEL) (Hendricks and Bulder 1995). A DEL was calculated for each station of the blade that failed during the course of testing. The DEL as calculated here is based on moment range - mean load effects are ignored. Eq. 5 provides the DEL formula and equation variables used in the analysis. 


$$
D E L=\left(\sum_{i} \frac{M_{i}^{m}}{N_{e q}}\right)^{\frac{1}{m}}
$$

where:

$$
\begin{array}{ll}
D E L & =\text { damage equivalent load }[\mathrm{kN}-\mathrm{m}] \\
M_{i} & =\text { Applied moment range of an individual test cycle }[\mathrm{kN}-\mathrm{m}] \\
N_{e q} & =\text { Number of constant amplitude cycles }\left(N_{e q}=250,000\right) \\
m & =\text { Inverse S-N slope (here: } m=10 \text { for fiberglass, } m=14 \text { for carbon fiber). }
\end{array}
$$

Figure 20 provides the DEL at each of the failure stations. The DEL as shown includes all test moments applied at the respective station from all load cases and load blocks. The figure also indicates where notable observations were made from the AE system, and thermography. AE activity was based on the quantity and amplitude of hits. Significant AE activity was characterized by AE hit amplitudes above $70 \mathrm{~dB}$, or when the frequency of $\mathrm{AE}$ hits rose from several hits per fatigue cycle to hundreds or thousands of hits per cycle. A detailed assessment of the AE data was performed by SNL subcontractor Al Beattie (Beattie 2013b). Thermal hotspots were indicated when the temperature of a location on the blade (flaw location) was observed to be several degrees above the temperature of the surrounding blade surface.

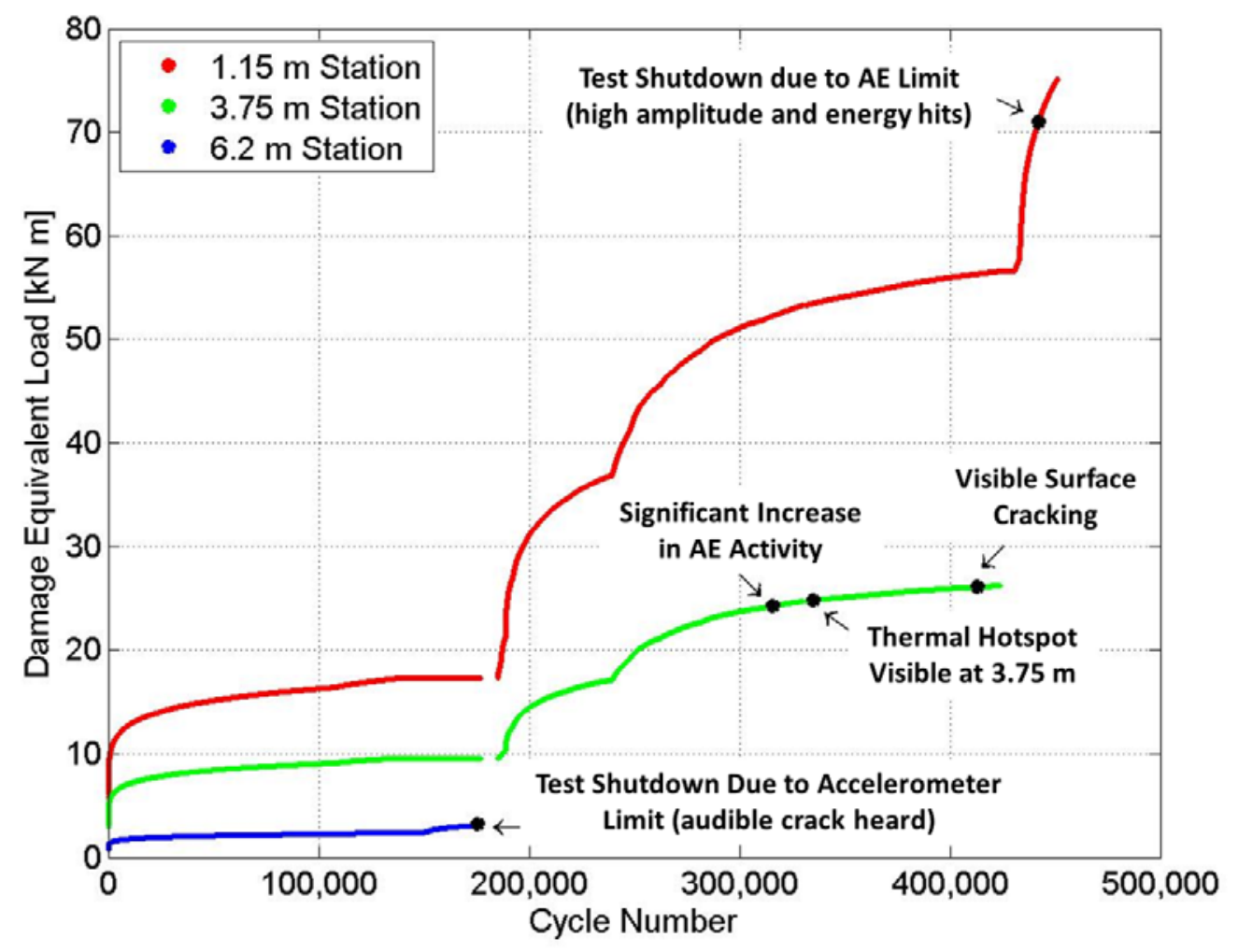

Figure 20. Fiberglass spar cap blade, damage equivalent load curves for each failure station 
Table 2 provides the nominal strains as measured by the resistance-type strain gages located on the blade spar cap. Again, these gages were not located on specific flaws, but in spanwise regions in between flaw locations. Table 2 also provides the corresponding deflections at the actuator load application station. The nominal moments, strains, and displacements are given for the largest test moment applied in each of the load cases, averaged over a period of 1,000 test cycles. Detailed information on each of the load cases can be found in the laboratory test report (Desmond 2014).

Table 2. Nominal Resistance-Type Strains and Blade Displacements at the Load Application Station for the Fiberglass Spar Cap Blade

\begin{tabular}{|l|c|c|c|c|c|}
\hline Load Case & $\begin{array}{c}\text { Load } \\
\text { Application } \\
\text { Station [m] }\end{array}$ & $\begin{array}{c}\text { Strain Gage } \\
\text { Location }\end{array}$ & $\begin{array}{c}\text { Nominal } \\
\text { Strain Range } \\
\text { [microstrains] }\end{array}$ & $\begin{array}{c}\text { Moment at } \\
\text { strain gage } \\
\text { station [kN- } \\
\mathrm{m} \text { ] }\end{array}$ & $\begin{array}{c}\text { Nominal } \\
\text { Actuator } \\
\text { Displacement } \\
\text { Range [m] }\end{array}$ \\
\hline \multirow{2}{*}{$\begin{array}{l}\text { Outboard- } \\
\text { span }\end{array}$} & $7 \mathrm{~m}$ & $5.25 \mathrm{~m}, \mathrm{LP}$ side & 4,613 & \multirow{2}{*}{5.84} & 0.59 \\
\cline { 2 - 4 } & $5.25 \mathrm{~m}, \mathrm{HP}$ side & 4,207 & \multirow{2}{*}{29.84} & 0.59 \\
\hline \multirow{2}{*}{ Midspan } & $6 \mathrm{~m}$ & $3.5 \mathrm{~m}$, LP side & 5,129 & \\
\cline { 2 - 4 } & $3.5 \mathrm{~m}, \mathrm{HP}$ side & 4,858 & & \\
\hline
\end{tabular}




\section{Testing the Carbon Fiber Spar Cap Blade}

The carbon fiber spar cap blade was cut at the 7.1-m station, with the blade cavity filled with epoxy, to directly attach the actuator to apply the outboard load case at the 7-m station. The first load block applied a cyclic load with a maximum load of $1.4 \mathrm{kN}$ and a minimum load of $0.1 \mathrm{kN}$. The maximum and minimum loads were increased over 10 different load blocks encompassing 154,546 test cycles, with the final load block applying a maximum cyclic load of $5.1 \mathrm{kN}$ and a minimum load of $0.5 \mathrm{kN}$. The blade was then clamped at the 6-m station for several load blocks because the required test displacement exceeded the displacement capacity of the actuator. Test loads were applied at frequencies ranging between 0.8 and $1.0 \mathrm{~Hz}$. Fatigue loading continued until a blade failure occurred on the low-pressure surface at the $6.2-\mathrm{m}$ station. Figure 21 shows the test bending moment range applied to the 6.2-m station for all load blocks applied at the 7-m station.

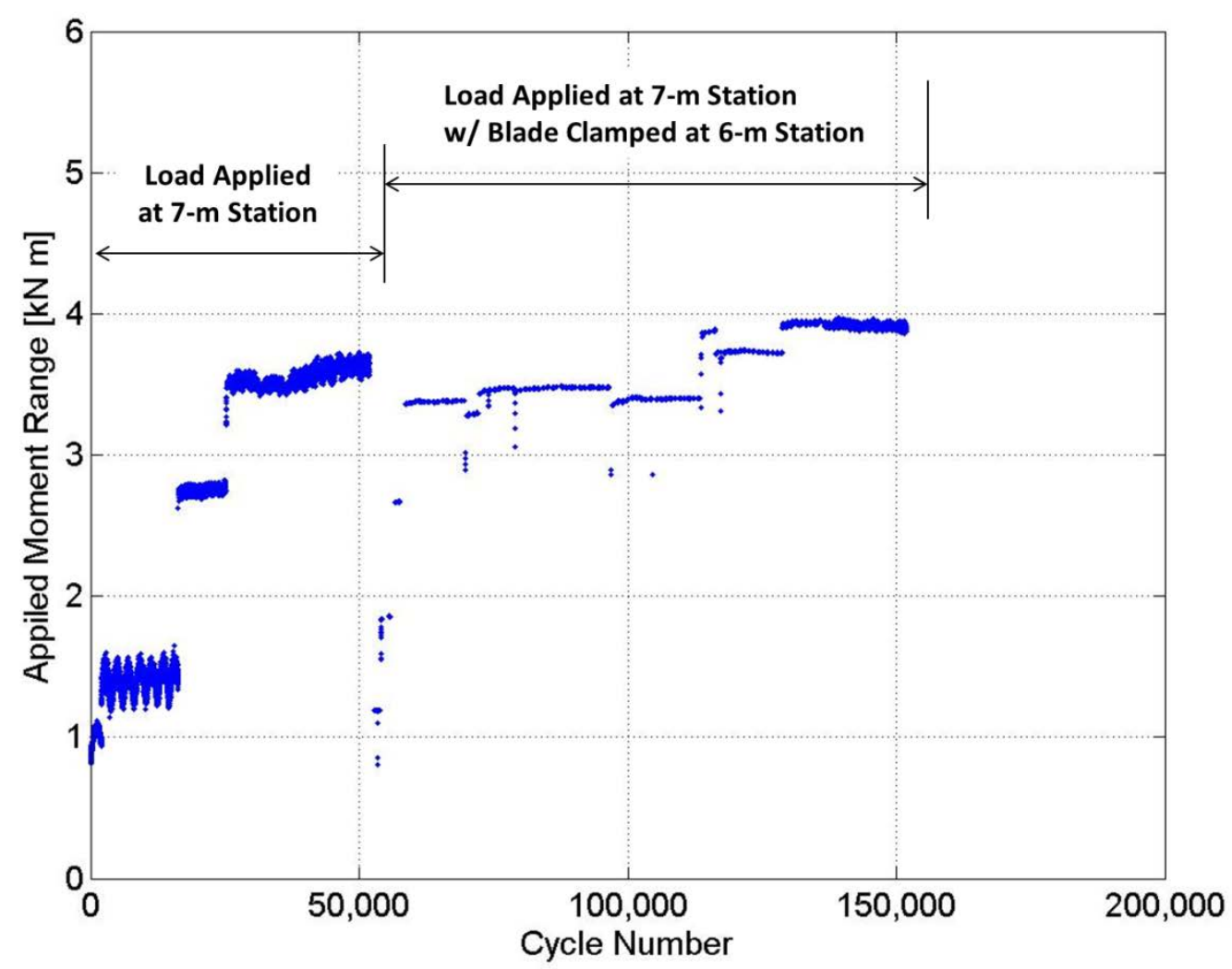

Figure 21. Moment range versus cycle number at the 6.2-m station, carbon fiber spar cap blade

Figure 22 shows a photograph of the failure region on the low-pressure surface at the 6.2-m station. The paint used for DIC imaging had been removed to show the physical characteristics of the blade and failure area. The failure location of $6.2-\mathrm{m}$ coincides with the location of an outof-plane wave in the spar cap. Visual indications on the surface of the blade show matrix cracking across the width of the spar cap, cracks in the composite across the width of the spar cap that radiate into the leading-edge and trailing-edge panels. Light areas can be seen in the photo and are likely due to delaminations through the thickness of the composite. 


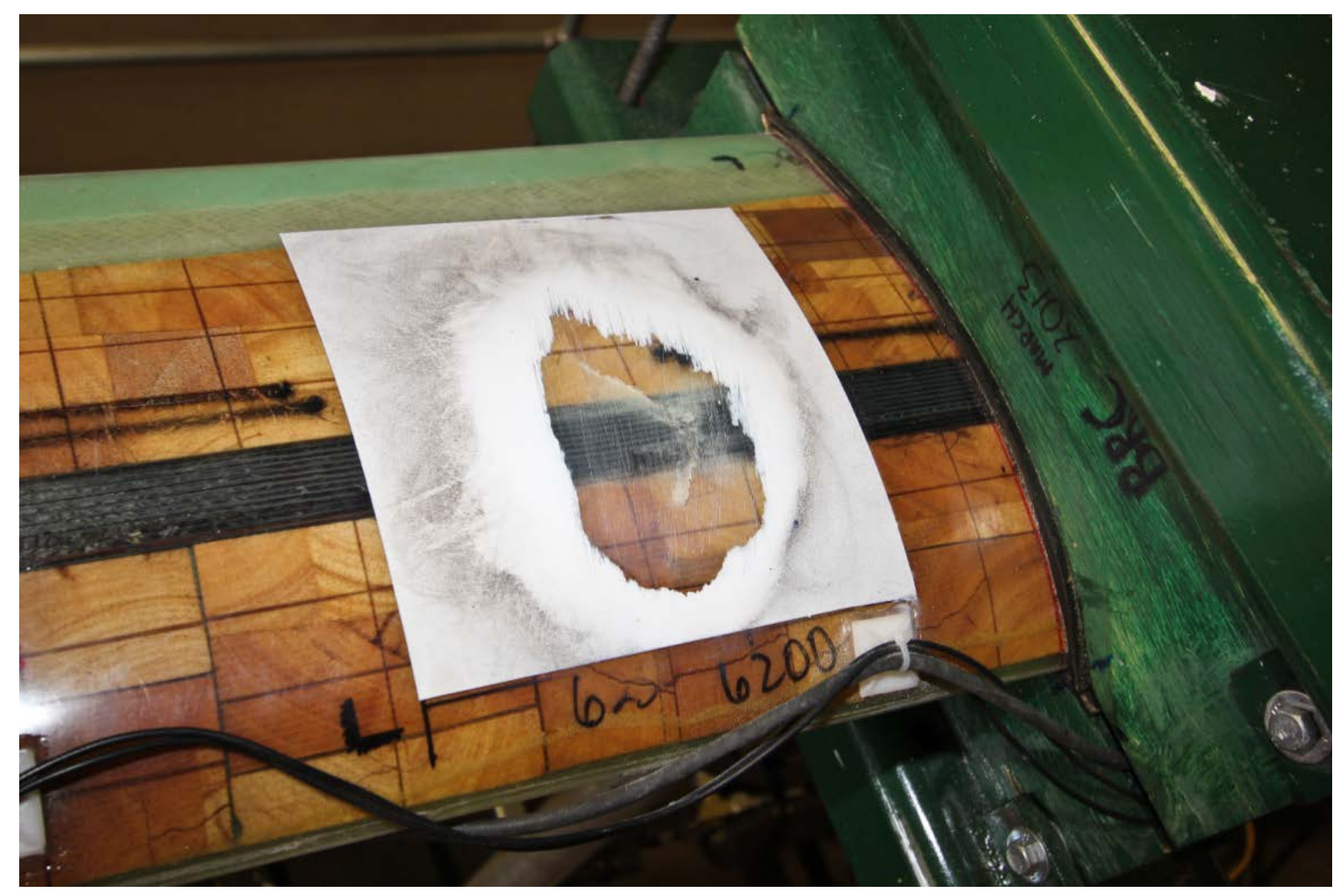

Figure 22. Carbon fiber spar cap blade, low-pressure side failure area at the 6.2-m station. Photo by Michael Desmond, NREL 32528

After the blade failed at the 6.2-m station, the blade tip was cut from the blade and the test was configured to apply loads at the 6-m station for the midspan load case. A load saddle was attached to the blade for applying actuator loads. During the midspan load case, the blade was subjected to a total of 278,913 test cycles. Loads were applied with a test cycle frequency of 0.75 Hz. The amplitude of the actuator force for the mid-span load blocks ranged from an initial range of $3.2 \mathrm{kN}$ maximum and $0.3 \mathrm{kN}$ minimum to the final load block that applied loads of 11.2 maximum and $1.1 \mathrm{kN}$ minimum. DIC imaging was not performed during loading at the $6-\mathrm{m}$ station. The blade failed during the final load block on the low-pressure surface at the 5-m station. Figure 23 shows the test bending moment range applied at the 5-m station, including loads applied at both the 6-m and 7-m stations. The total cycle count including load cases applied at both the 6-m and 7-m stations was 433,459 cycles. 


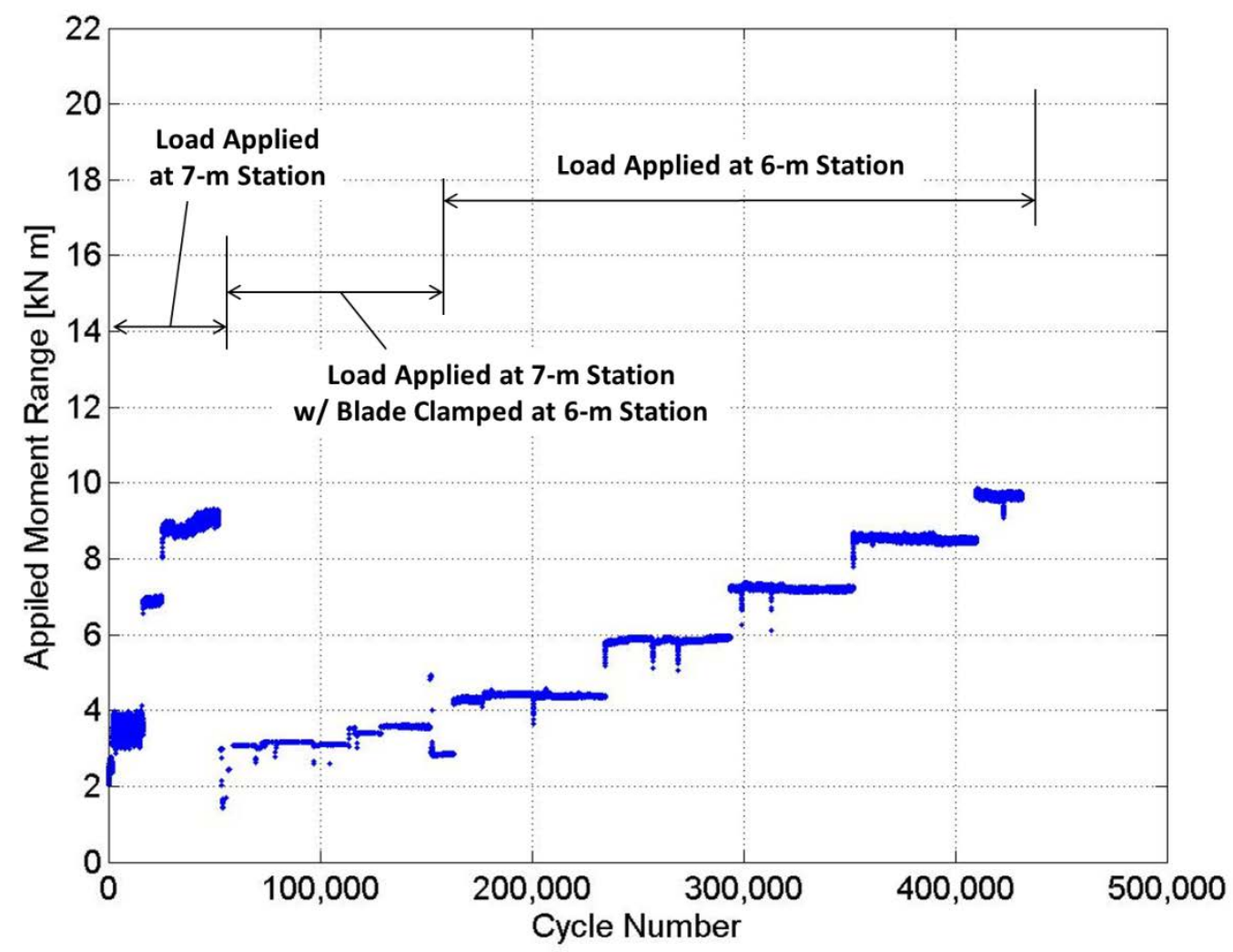

Figure 23. Moment range versus cycle number at the 5-m station, carbon fiber spar cap blade

Figure 24 shows a photograph of the failure region on the low-pressure surface at the 5-m station. The failure location of $5 \mathrm{~m}$ coincides with the location of an in-plane wave built into the low-pressure side spar cap. Visual indications on the surface of the blade show matrix cracking across the width of the spar cap, cracks in the composite across the width of the spar cap with the final catastrophic failure cracking the entire low-pressure surface from the leading edge to the trailing edge. Light areas can be seen in the photo and are likely caused by delaminations through the thickness of the composite. These light-colored areas in the spar cap are closely confined in the region of the failure. 


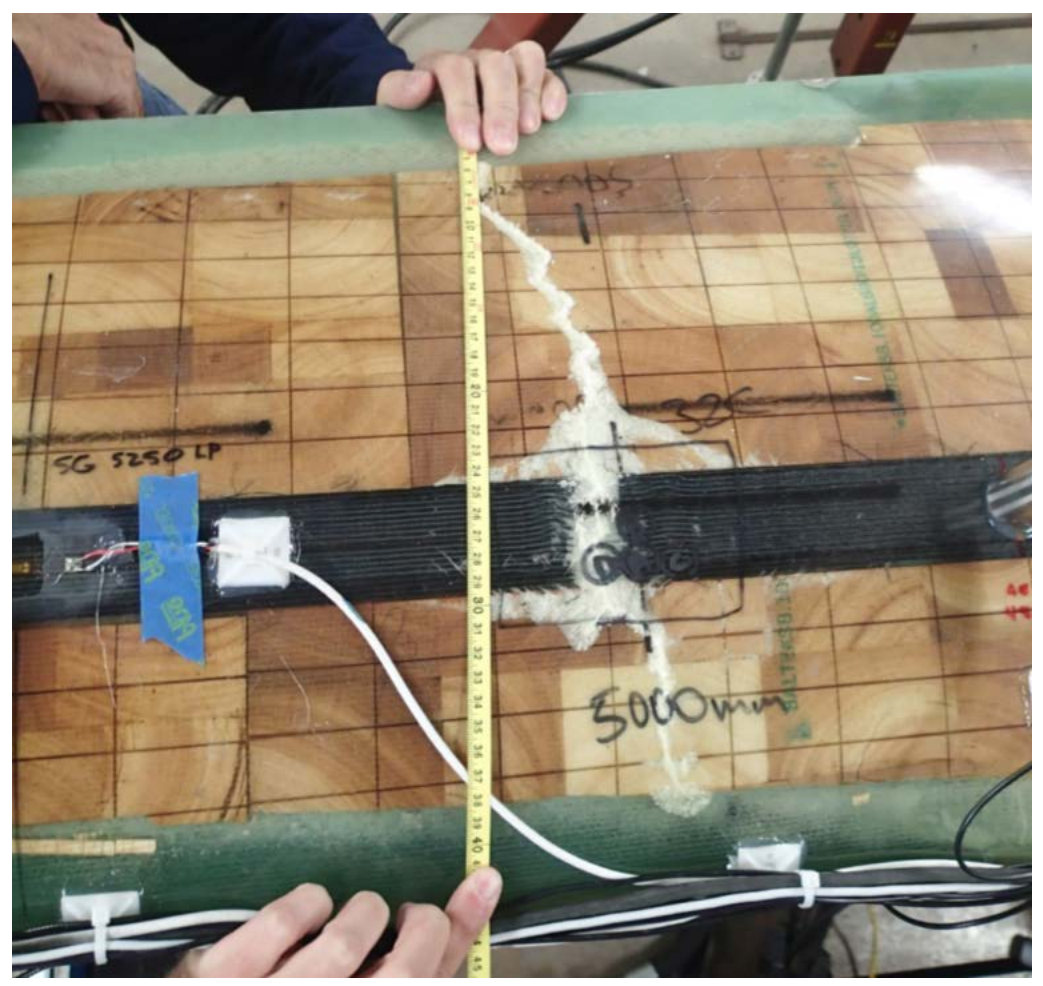

Figure 24. Carbon fiber spar cap blade, failure region on low-pressure surface at the 5-m station. Photo by Mike Jenks, NREL 32529

Figure 25 provides the DEL at each of the failure stations for testing the carbon fiber spar cap blade. The DEL as shown includes all test moments applied at the respective station from all load cases and load blocks. The figure also indicates where notable observations were made from the AE, thermography, and DIC systems. Similar to the fiberglass spar cap blade, AE activity was seen to increase prior to detecting damage by visible observation. One interesting difference was that the number of AE hits observed during the carbon fiber spar cap blade was an order of magnitude less than the hits observed during the fiberglass spar cap blade test. This difference may suggest that the damage to the embedded defects in the carbon fiber spar cap blade were more abrupt and progressed faster than damage to the embedded defects in the fiberglass spar cap blade. 


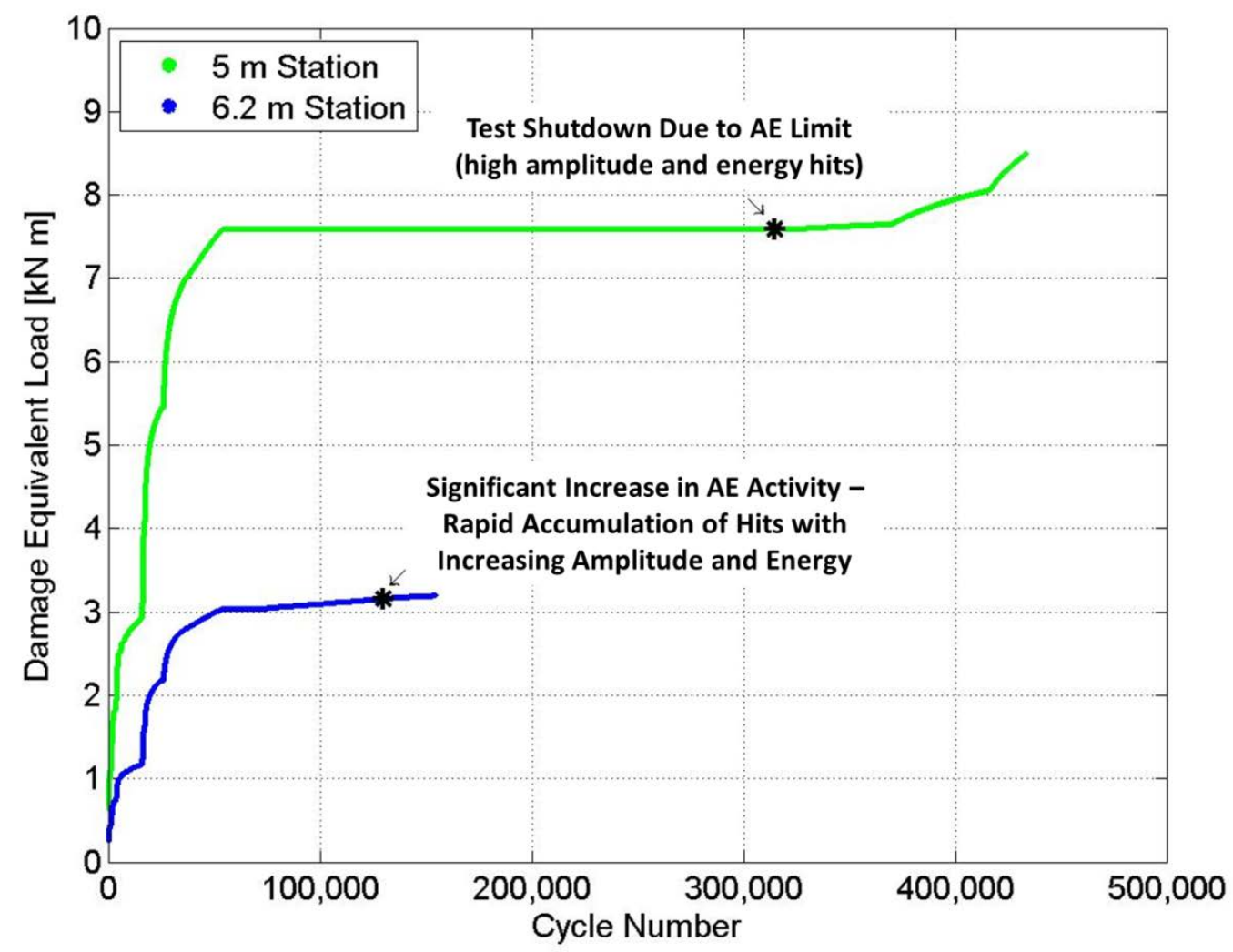

Figure 25. Carbon fiber spar cap blade, DEL curves at failure stations of $5 \mathrm{~m}$ and $6.2 \mathrm{~m}$

Following completion of the midspan fatigue load case, it was determined that a static load to failure would be conducted on the inboard span of the blade using a single point-load applied at the $4.37-\mathrm{m}$ station. The load was applied by a hydraulic actuator in discrete load steps until a catastrophic failure occurred on the low-pressure surface of the blade at the 2.25 -m station. Figure 26 shows the force versus time data for each of the static load steps up to failure. 


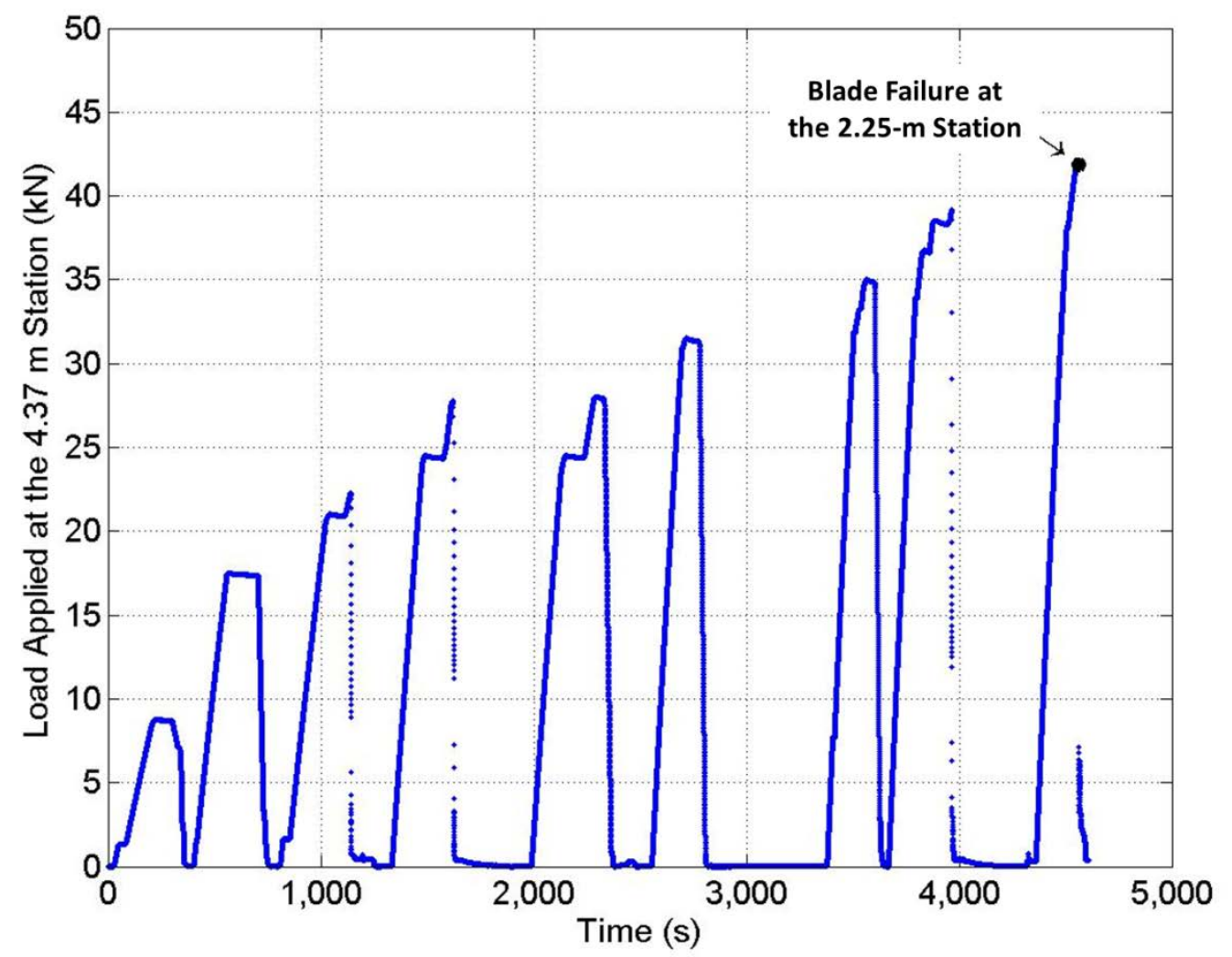

Figure 26. Static load steps applied at the 4.37-m station, carbon spar cap blade

Figure 27 shows a photograph of the failure area. The maximum static bending moment achieved at the $2.25-\mathrm{m}$ station during static loading was $88.8 \mathrm{kN}-\mathrm{m}$. The failure appeared to be buckling with significant damage to the spar cap and cracking of the entire low-pressure surface from the leading edge to the trailing edge. 


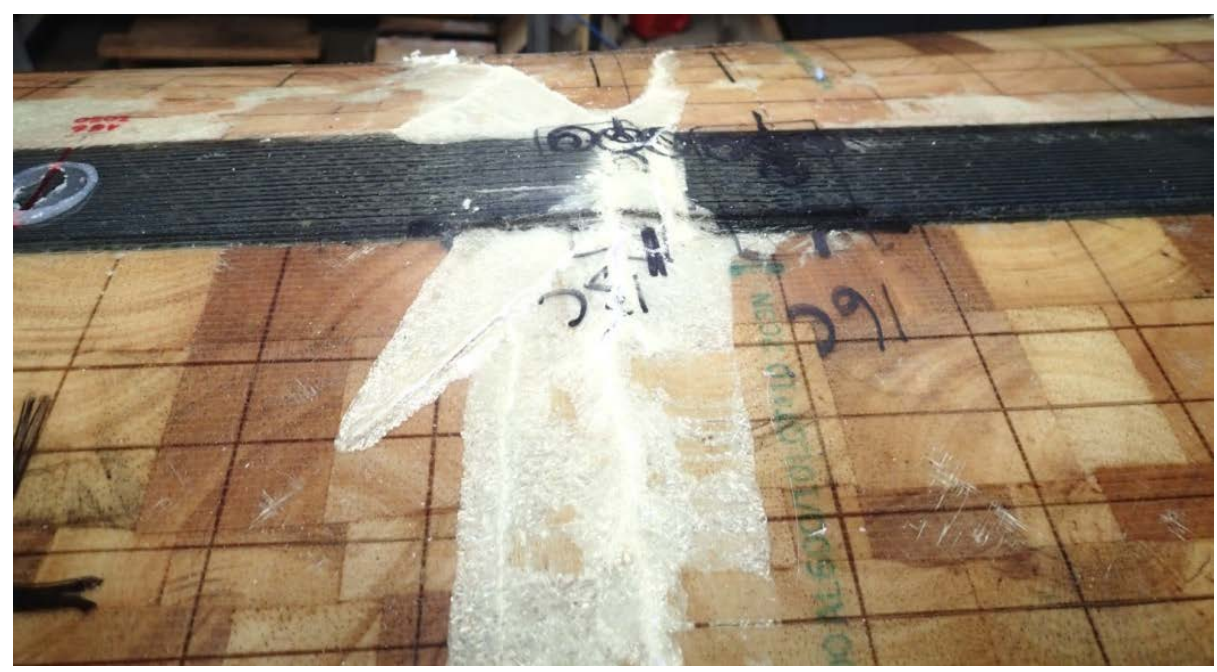

Figure 27. Failure area on the low-pressure side at the 2.25-m station, carbon fiber spar cap blade. Photo by Michael Desmond, NREL 32530

Table 3 provides the nominal strains as measured by the resistance-type strain gages during testing of the carbon spar cap blade. Table 3 also provides the corresponding deflections at the actuator load application station. The nominal moments, strains, and displacements are given for the largest test moment applied at the respective stations, averaged over a period of 1,000 test cycles. For the inboard load case, with high strains in the inboard span of the blade, the table shows the maximum recorded strain levels and actuator displacement at the time of failure during the static load test.

Table 3. Nominal Resistance-Type Strains and Blade Displacements at the Load Application Station for the Carbon Fiber Spar Cap Blade

\begin{tabular}{|c|c|c|c|c|c|}
\hline Load Case & $\begin{array}{c}\text { Load } \\
\text { Application } \\
\text { Station }[\mathrm{m}]\end{array}$ & $\begin{array}{c}\text { Strain Gage } \\
\text { Location }\end{array}$ & $\begin{array}{c}\text { Nominal } \\
\text { Strain Range } \\
\text { [microstrains] }\end{array}$ & $\begin{array}{c}\text { Moment at } \\
\text { Strain Gage } \\
\text { Station } \\
{[\mathrm{kN}-\mathrm{m}]}\end{array}$ & $\begin{array}{c}\text { Nominal } \\
\text { Actuator } \\
\text { Displacement } \\
\text { Range }[\mathrm{m}]\end{array}$ \\
\hline \multirow{2}{*}{$\begin{array}{l}\text { Outboard- } \\
\text { span }\end{array}$} & \multirow[t]{2}{*}{$7 \mathrm{~m}$} & $5.25 \mathrm{~m}$ LP side & 5,222 & \multirow[t]{2}{*}{7.73} & \multirow[t]{2}{*}{0.67} \\
\hline & & $5.25 \mathrm{~m} \mathrm{HP}$ side & 4,805 & & \\
\hline \multirow{2}{*}{ Midspan } & \multirow{2}{*}{$6 \mathrm{~m}$} & 3.75 m LP side & 5,076 & 21.75 & \multirow{2}{*}{0.43} \\
\hline & & 3.7 $\mathrm{m} \mathrm{HP}$ side & 3,877 & 22.19 & \\
\hline \multirow{2}{*}{$\begin{array}{l}\text { Inboard- } \\
\text { span (static } \\
\text { load } \\
\text { application) }\end{array}$} & \multirow{2}{*}{$4.37 \mathrm{~m}$} & 2.75 m LP side & 10,292 & \multirow{2}{*}{67.83} & \multirow[b]{2}{*}{0.34} \\
\hline & & $2.75 \mathrm{~m}$ HP side & 7,318 & & \\
\hline
\end{tabular}




\section{Summary}

Wind turbine blades that were $8.3 \mathrm{~m}$ long, with flaws intentionally built into the structural laminate, were tested to failure. Two blades were tested, one blade was manufactured with a fiberglass spar cap and the second blade was manufactured with a carbon fiber spar cap. Testing focused on loading specific spanwise areas of the blade that contained the intentional defects. The experiments successfully tested to failure multiple embedded flaws. Each failure region with embedded flaws contained either in-plane or out-of plane waves in the spar cap of the blade. Table 4 provides a summary of the applied test loading at the time of failure for each of the embedded flaws. Figure 28 provides a chart of the DEL at failure for each of the fatigue failure locations, compared with the target bending moment distributions for both the fiberglass and carbon fiber blades.

Table 4. Summary of Failures Observed During Full-Scale Structural Testing of the BRC Blades

\begin{tabular}{|l|c|c|c|c|l|}
\hline \multicolumn{1}{|c|}{ Blade } & $\begin{array}{c}\text { Loading } \\
\text { Station } \\
{[\mathrm{m}]}\end{array}$ & $\begin{array}{c}\text { Failure } \\
\text { Station } \\
{[\mathrm{m}]}\end{array}$ & $\begin{array}{c}\text { Failure } \\
\text { Side }\end{array}$ & $\begin{array}{c}\text { DEL at } \\
\text { Failure } \\
{[\mathbf{k N} \text {-m] }}\end{array}$ & \multicolumn{1}{|c|}{ Flaw at Station } \\
\hline $\begin{array}{l}\text { Fiberglass } \\
\text { spar cap }\end{array}$ & 7 & 6.2 & LP & 3.18 & $\begin{array}{l}\text { Out-of-plane wave in } \\
\text { spar cap }\end{array}$ \\
\hline $\begin{array}{l}\text { Fiberglass } \\
\text { spar cap }\end{array}$ & 6 & 3.75 & HP & 26.24 & $\begin{array}{l}\text { Out-of-plane wave in } \\
\text { spar cap }\end{array}$ \\
\hline $\begin{array}{l}\text { Fiberglass } \\
\text { spar cap }\end{array}$ & 3.5 & 1.2 & HP & 75.19 & $\begin{array}{l}\text { Root laminate } \\
\text { transition (not in the } \\
\text { set of intentional built- } \\
\text { in flaws) }\end{array}$ \\
\hline $\begin{array}{l}\text { Carbon } \\
\text { fiber spar } \\
\text { cap }\end{array}$ & 7 & 6.2 & LP & 3.19 & $\begin{array}{l}\text { Out-of-plane wave in } \\
\text { spar cap }\end{array}$ \\
\hline $\begin{array}{l}\text { Carbon } \\
\text { fiber spar } \\
\text { cap }\end{array}$ & 6 & 5 & LP & 8.49 & $\begin{array}{l}\text { In-plane wave in spar } \\
\text { cap }\end{array}$ \\
\hline $\begin{array}{l}\text { Carbon } \\
\text { fiber spar } \\
\text { cap }\end{array}$ & 4.37 & 2.25 & LP & $31.32^{*}$ & $\begin{array}{l}\text { In-plane wave in spar } \\
\text { cap }\end{array}$ \\
\hline
\end{tabular}

* Damage equivalent load applied prior to static load test. $88.8 \mathrm{kN}-\mathrm{m}$ static moment at failure. 


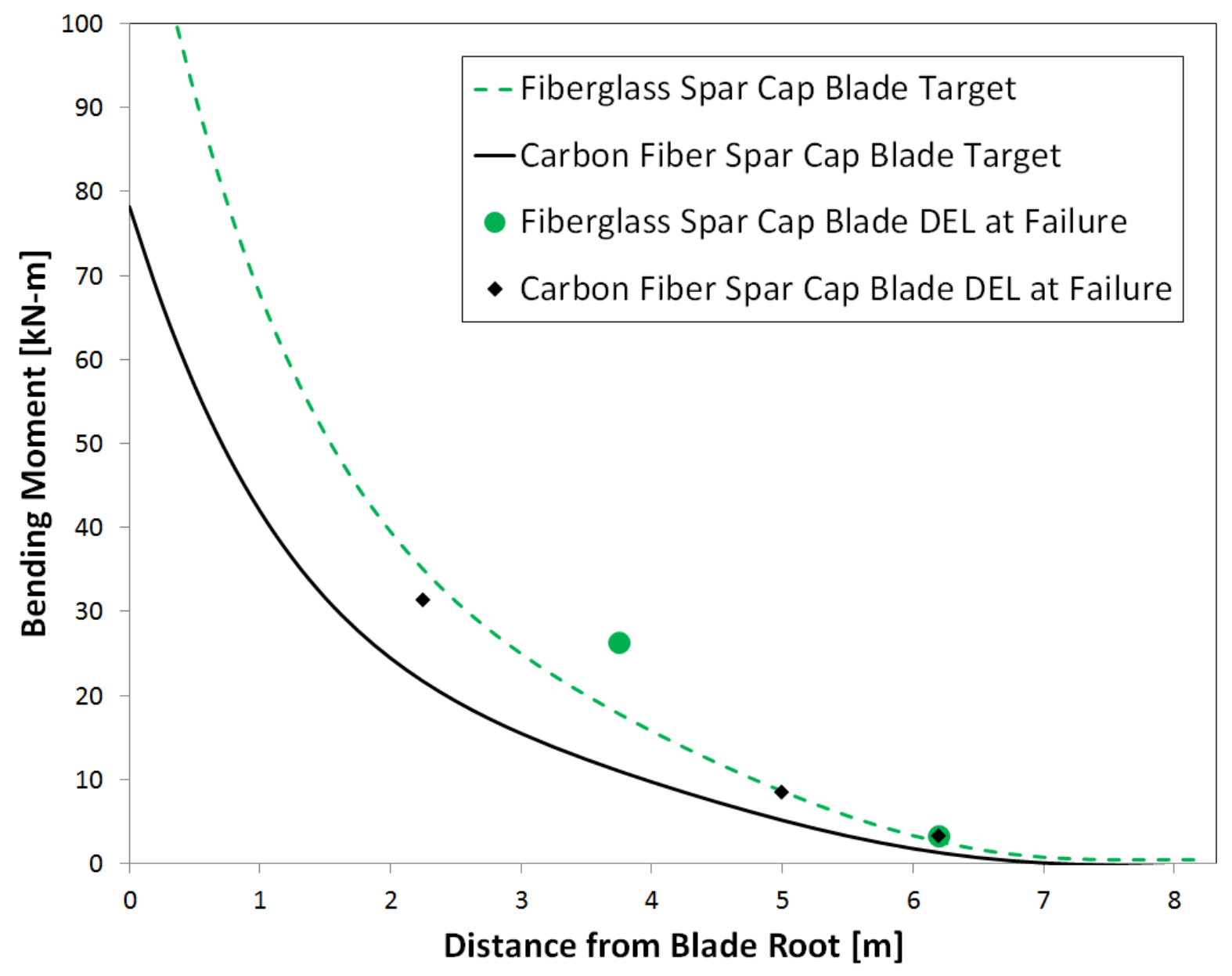

Figure 28. Comparison of target bending moment distribution and applied DEL at failure locations 


\section{References}

Beattie, A.G. (2013a). Acoustic Emission Non-Destructive Testing of Structures using Source Location Techniques. SAND2013-7779. Albuquerque, NM: Sandia National Laboratories .

Beattie, A.G. (2013b). Report on Acoustic Emission Monitoring of the Fatigue Tests of the BRC Wind Turbine Blades. Unpublished report.

Desmond, M. (2014). BRC Wind Turbine Blade Effects of Defects Fatigue Validation Testing. Blade Fatigue Test Summary Report. Report No. NWTC-BRC-141105. Unpublished test report.

Hendriks, H.B.; Bulder, B.H. (1995). Fatigue Equivalent Load Cycle Method - A General Method to compare the Fatigue Loading of Different Load Spectrums. Petten Netherlands Energy Research Foundation. ECN-C-95-074.

International Electrotechnical Commission (IEC). (2002). "IEC TS 61400-23, Wind Turbine Generator Systems - Part 23: Full-scale structural testing of rotor blades.” Geneva: IEC.

Musial, M.D.; Allread, J. (1993). "Test Methodology and Control of Full-scale Fatigue Tests on Wind Turbine Blades.” ASME Wind Energy Symposium Proceedings, 31 January-4 February 1993.

Musial, W.D.; Clark, M.E.; Stensland, T. (1996). "Application of BSTRAIN Software for Wind Turbine Blade Testing." NREL/TP-440-21507. Windpower 1996 Proceedings; June 23-27, 1996; Denver, CO. Washington D.C.: American Wind Energy Association; pp. 241-250.

Niezrecki, C. (2014). "Inspection and monitoring of wind turbine blade-embedded wave defects during fatigue testing." Journal of Structural Health Monitoring, (13:6) November 2014.

Paquette, J.; van Dam, J.; Hughes, S. (2007). "Structural Testing of $9 \mathrm{~m}$ Carbon Fiber Wind Turbine Research Blades.” AIAA 2007 Wind Energy Symposium, January 8, 2007.

Paquette, J. (2012). “Blade Reliability Collaborative.” http://energy.sandia.gov/wp/wpcontent/gallery/uploads/3-B-3-Paquette-SAND2012-5566C.pdf.

Riddle, T.W.; Cairns, D.S.; Nelson, J.W. (2011). "Characterization of Manufacturing Defects Common to Composite Wind Turbine Blades: Flaw Characterization." $52^{\text {nd }}$

AIAA/ASME/ASCE/AHS/ASC Structures, Structural Dynamics and Materials Conference. Denver, CO, April 4, 2011. 